\title{
Testing of the Crew Exploration Vehicle in NASA Langley's Unitary Plan Wind Tunnel
}

\author{
Kelly J. Murphy*, Stephen E. Borg ${ }^{\dagger}$, Anthony N. Watkins ${ }^{\ddagger}$ \\ NASA Langley Research Center \\ Hampton, VA 23681 \\ Daniel R. Cole $§$ \\ Jacobs Sverdrup, Inc \\ Hampton, VA 23681
}

Richard J. Schwartz ${ }^{* *}$

Swales Aerospace, Inc

Hampton, VA 23681

\begin{abstract}
As part of a strategic, multi-facility test program, subscale testing of NASA's Crew Exploration Vehicle was conducted in both legs of NASA Langley's Unitary Plan Wind Tunnel. The objectives of these tests were to generate aerodynamic and surface pressure data over a range of supersonic Mach numbers and reentry angles of attack for experimental and computational validation and aerodynamic database development. To provide initial information on boundary layer transition at supersonic test conditions, transition studies were conducted using temperature sensitive paint and infrared thermography optical techniques. To support implementation of these optical diagnostics in the Unitary Wind Tunnel, the experiment was first modeled using the Virtual Diagnostics Interface software. For reentry orientations of 140 to 170 degrees (heat shield forward), windward surface flow was entirely laminar for freestream unit Reynolds numbers equal to or less than 3 million per foot. Optical techniques showed qualitative evidence of forced transition on the windward heat shield with application of both distributed grit and discreet trip dots. Longitudinal static force and moment data showed the largest differences with Mach number and angle of attack variations. Differences associated with Reynolds number variation and/or laminar versus turbulent flow on the heat shield were very small. Static surface pressure data supported the aforementioned trends with Mach number, Reynolds number, and angle of attack.
\end{abstract}

\section{Nomenclature}

AF Axial force (lbs)

$\mathrm{C}_{\mathrm{A}} \quad$ Axial-force coefficient, $\mathrm{AF} / \mathrm{qS}_{\mathrm{ref}}$

$\mathrm{C}_{\mathrm{D}} \quad$ Drag-force coefficient, $\mathrm{C}_{\mathrm{A}} \cos \square+\mathrm{C}_{\mathrm{N}} \sin \square$

$\mathrm{C}_{\mathrm{L}} \quad$ Lift-force coefficient, $\mathrm{C}_{\mathrm{N}} \cos \square-\mathrm{C}_{\mathrm{A}} \sin \square$

$\mathrm{C}_{\mathrm{m}} \quad$ Pitching-moment coefficient, $\mathrm{PM} / \mathrm{qS} \mathrm{S}_{\mathrm{ref}} \mathrm{L}_{\text {ref }}$

\footnotetext{
* Aerospace Engineer, Aerothermodynamics Branch, Mail Stop 408A

$\dagger$ Aerospace Engineer, Advanced Sensing and Optical Measurement Branch, Mail Stop 493.

$\$$ Aerospace Engineer, Advanced Sensing and Optical Measurement Branch, Mail Stop 493.

$\S$ Wind Tunnel Test Engineer, Jacobs Sverdrup, Inc, Mail Stop 413.

** Aerospace Engineer, Swales Aerospace, Inc, Mail Stop 493.
}

This material is declared a work of the U.S. Government and is not subject to copyright protection in the United States. Published by the American Institute of Aeronautics and Astronautics, Inc., with permission 
$\mathrm{C}_{\mathrm{N}} \quad$ Normal-force coefficient, $\mathrm{NF} / \mathrm{qS} \mathrm{S}_{\text {ref }}$

$\mathrm{C}_{\mathrm{N} \square} \quad \mathrm{dC}_{\mathrm{N}} / \mathrm{d} \square$, Normal-force curve slope

$\mathrm{C}_{\mathrm{P}} \quad$ Static pressure coefficient, $\left(\mathrm{p}-\mathrm{p}_{\infty}\right) / \mathrm{q}_{\infty}$

D Vehicle diameter (in)

d Model diameter (in.)

ID Inside diameter (in.)

K Distributed roughness height (in.)

$\mathrm{L}_{\mathrm{ref}} \quad$ Longitudinal reference length (in.)

L/D Lift-to-Drag Ratio

mrc moment reference center

M Freestream Mach number

M1 Freestream Mach number

$\mathrm{M}_{2} \quad$ Post-shock Mach number

OD Outside diameter (in.)

$\mathrm{p} \quad$ Model surface static pressure (psf)

$\mathrm{p}_{\infty} \quad$ Freestream static pressure $(\mathrm{psf})$

$\mathrm{P}_{\mathrm{T}} \quad$ Freestream total pressure (psf)

PT1 Freestream total pressure (psf)

$\mathrm{P}_{\mathrm{T} 2} \quad$ Post-shock total pressure (psf)

q Freestream dynamic pressure (psf)

$\mathrm{q}_{\infty} \quad$ Freestream dynamic pressure (psf)
Re Freestream unit Reynolds number, per $\mathrm{ft}$

$\mathrm{Re}_{1} \quad$ Freestream unit Reynolds number

$\mathrm{Re}_{2}$ Post-shock unit Reynolds number

$\mathrm{Re}_{\mathrm{d}} \quad$ Reynolds number based on model diameter

$\mathrm{S}_{\text {ref }} \quad$ Model reference area (sq. in.)

$\mathrm{T}_{\mathrm{T}} \quad$ Freestream total temperature $\left({ }^{\circ} \mathrm{F}\right)$

TT1 Freestream total temperature $\left({ }^{\circ} \mathrm{F}\right)$

$\mathrm{T}_{\mathrm{T} 2} \quad$ Post-shock total temperature $\left({ }^{\circ} \mathrm{F}\right)$

TS Test section

$\mathrm{x} \quad$ Surface running length (in.)

$X \quad$ Body-axis reference coordinate

$\mathrm{X} / \mathrm{D} \quad$ Non-dimensional $\mathrm{X}$-value of pressure tap

Xmrc X-coordinate of mrc (in.)

$\mathrm{Y} \quad$ Body-axis reference coordinate

Ymrc Y-coordinate of mrc (in.)

$\mathrm{Z} \quad$ Body-axis reference coordinate

Zmrc Z-coordinate of mrc (in.)

Angle of attack (deg.)

Angle of sideslip (deg.)

Radial reference coordinate

Standard deviation

\section{Introduction}

A new spacecraft for human space exploration, the Crew Exploration Vehicle (CEV), recently named "Orion" is being developed by the National Aeronautics and Space Administration (NASA) with support from industry partners. The CEV is designed to deliver crews and supplies to and from the International Space Station, carry four astronauts to and from the moon, and support up to six crewmembers on future missions to Mars. The CEV shape is derived from the Apollo capsule, as blunt-body, conical spacecraft are thought to provide the safest, most economical means of transporting crews to and from space. With a diameter of approximately 5 meters, the CEV will have over 2.5 times the volume of the Apollo capsules (Fig. 1). This design will shorten development time, reduce reentry loads, and increase landing stability, resulting in a spacecraft ten times safer than the current Space Shuttle, scheduled to be retired in 2010. First flights of the CEV are currently planned for no later than 2014, minimizing the gap in human space flight. ${ }^{1}$

The aerodynamic database for the Crew Exploration Vehicle is required for the development and analysis of flight trajectories, control systems, structural design, and in conjunction with the aerothermal database, the overall thermal analysis and thermal protection system design. The initial database will cover nominal return from low-Earth orbit and lunar missions, on-orbit operations, and ascent abort post-separation from the Crew Launch Vehicle (CLV), recently names "Ares," and Launch Abort System (LAS) to include any proximity effects from other CLV/LAS hardware. The databases will also capture reaction control system jet increments for associated flight phases.

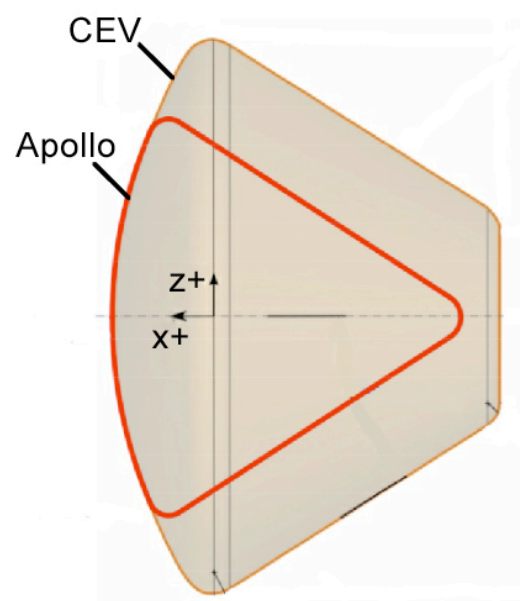

Figure 1. Apollo (with apex cover) and CEV outermold-line notional comparison. 
A strategic wind-tunnel test program is underway at facilities throughout the country to support several phases of aerodynamic database development. Initial static and dynamic force and moment tests have been performed in the subsonic, transonic, supersonic, and hypersonic speed regimes focused on reentry aerodynamics. In the subsonic, transonic and supersonic regimes, companion static and dynamic surface pressure data have also been generated. Both discrete pressure and integrated force and moment data are being used to validate existing computational methods so that both computational fluid dynamics (CFD) codes and wind tunnel data may be used synergistically to develop the complete aerodynamic database for the CEV.

\section{Objectives}

A test program to generate both static aerodynamic and static surface pressure data for the current CEV configuration at supersonic reentry conditions was executed in the Unitary Plan Wind Tunnel (UPWT) at the NASA Langley Research Center (LaRC). The objectives (as addressed chronologically) of the multi-entry test program were as follows:

(1) Characterize the boundary layer state for CEV at supersonic test conditions. To provide initial information on boundary layer state and transition characteristics at supersonic test conditions prior to generation of aerodynamic and pressure data, transition studies were conducted in Langley's UPWT using both temperature sensitive paint (TSP) and infrared (IR) thermography optical techniques with the support of Virtual Diagnostics Interface (ViDI) modeling techniques.

(2) Generate longitudinal static aerodynamic data for the CEV configuration at supersonic test conditions for a range of attitude, configuration, and flow field parametrics. To accomplish this objective, a solid aluminum sub-scale CEV model was designed and fabricated for testing in the LaRC UPWT. Longitudinal force and moment data were generated using a standard 6-component strain-gage force and moment balance. This data set was designed to complement CEV test program 5- $\mathrm{CA}^{3}$, conducted in the Ames Unitary Plan Wind Tunnel at similar conditions.

(3) Generate surface static pressure information for the CEV configuration at supersonic test conditions for a range of attitude, configuration, and flow field parametrics. Surface pressure data were generated via 81 internal static surface pressure orifices and off-board pressure instrumentation. This test program was designed to complement CEV Test 5-CA ${ }^{2}$ conducted in the Ames Unitary Plan Wind Tunnel and enhance the understanding of aerodynamic data generated both at NASA LaRC (described herein) as well as at NASA ARC.

\section{Configuration Description}

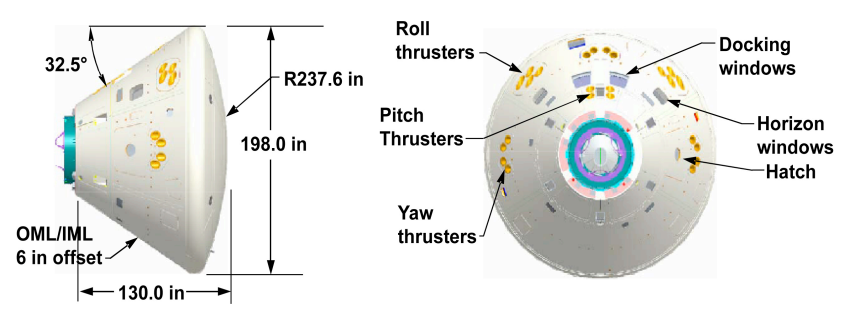

Figure 2. CEV “Orion" crew module.

Table 1. CEV reference dimensions.

\begin{tabular}{|l|l|ll|l|}
\hline Constant & Name & \multicolumn{2}{|l|}{ Full-Scale } & 3.03\%-Scale \\
\hline \hline Vehicle Diameter & D & $16.5 \mathrm{ft}$. & $(5.0 \mathrm{~m})$ & $6.0 \mathrm{in}$ \\
\hline Reference Length & Lref & $16.5 \mathrm{ft}$. & $(5.0 \mathrm{~m})$ & $6.0 \mathrm{in}$ \\
\hline Reference Area & Sref & $213.8 \mathrm{ft}^{2}$ & $\left(19.6 \mathrm{~m}^{2}\right)$ & $28.27 \mathrm{in}^{2}$ \\
\hline Moment Reference, $\mathrm{X}$ & Xmrc & $11.1 \mathrm{ft}$ & $(3.38 \mathrm{~m})$ & $4.05 \mathrm{in}$ \\
\hline Moment Reference, $Y$ & Ymrc & 0 & & 0 \\
\hline Moment Reference, $Z$ & Zmrc & $-0.74 \mathrm{ft}$ & $(0.23 \mathrm{~m})$ & $-0.288 \mathrm{in}$ \\
\hline
\end{tabular}

As seen in Figure 1, the CEV "Orion" Crew Module $(\mathrm{CM})$ is principally derived from the blunt capsule shape of the Apollo crew module. The schematic in Figure 2 shows the capsule maximum diameter is 198 in $(5.0 \mathrm{~m})$, yielding an internal volume of $698.1 \mathrm{ft}^{3}\left(19.8 \mathrm{~m}^{3}\right)$, more than 2.5 times that of the Apollo capsule. The configuration's length is 130 in $(3.3 \mathrm{~m})$ and the back-shell angle is $32.5^{\circ}$ $\left(0.5^{\circ}\right.$ smaller than the Apollo configuration). The heat shield radius is 237.6 in. $(6.0 \mathrm{~m})$ with shoulder radii of 10.8 in. $(0.275 \mathrm{~m})$. The dry weight of the CEV CM is $17,400 \mathrm{lbs}$. Table 1 shows a summary of reference dimensions for the full-scale CEV as well as the $3.03 \%$-scale models used in the current test program. It is important to note that moment reference values shown below represent a realistic estimate of the vehicle's flight center of gravity. As the vehicle's design and databases mature, these reference values will be adjusted. 


\section{Experimental Program}

\section{$\underline{\text { Facility }}$}

The LaRC UPWT is a closed-circuit, continuous-running, pressure tunnel with two test sections that are nominally $4 \mathrm{ft}$ by $4 \mathrm{ft}$ in cross section and 7-ft long. The stagnation pressure can be varied up to a maximum of approximately 50 psia in Test Section (TS) I and approximately 100 psia in Test Section II. The nozzle throat-totest-section area ratio is varied by a lower asymmetric sliding nozzle block that provides continuous variation of the Mach number. The Mach number range is nominally 1.5 to 2.86 in Test Section I and 2.3 to 4.63 in Test Section II. Tunnel stagnation temperatures are typically $125^{\circ} \mathrm{F}$ and $150^{\circ} \mathrm{F}$ for each test section, respectively. Reynolds numbers from 1.0 to 6.0 million per foot can be run routinely with a capability to reach 7.0 million per foot on a transient basis. Nominal flow conditions for CEV testing are shown in Table 2. The basic model support mechanism is a horizontal wall-mounted strut that is capable of forward and aft travel of over $3 \mathrm{ft}$ in the stream-wise direction. A main sting support attached to the strut can transverse laterally \pm 20 in and can provide a yaw capability of $\pm 12^{\circ}$. Forward of the main sting support is the angle-of-attack mechanism that provides pitch motion from $-15^{\circ}$ to $+30^{\circ}$. A roll mechanism can be installed ahead of the pitch mechanism to provide continuous roll motion over a $310^{\circ}$ range. $^{3}$

Table 2. Nominal flow conditions for CEV testing in LaRC UPWT.

\begin{tabular}{|c|c|c|c|c|c|}
\hline TS & $\mathbf{M}$ & $\mathbf{q}(\mathbf{p s f})$ & $\mathbf{P}_{\mathbf{T}}(\mathbf{p s f})$ & $\left.\mathbf{T}_{\mathbf{T}}{ }^{\circ} \mathbf{F}\right)$ & $\mathbf{R e} / \mathbf{f t}$ \\
\hline \hline I & 1.6 & 682.2 & 1618 & 125 & $3.0 \times 10^{6}$ \\
\hline I & 1.8 & 683.3 & 1731 & 125 & $3.0 \times 10^{6}$ \\
\hline I & 2.0 & 672.8 & 1880 & 125 & $3.0 \times 10^{6}$ \\
\hline II & 2.5 & 652.4 & 2548 & 150 & $3.0 \times 10^{6}$ \\
\hline II & 3.0 & 570.1 & 3324 & 150 & $3.0 \times 10^{6}$ \\
\hline II & 4.0 & 409.2 & 5547 & 150 & $3.0 \times 10^{6}$ \\
\hline
\end{tabular}

\section{Models and Support Hardware}

Force and Moment: All experimental aerodynamic data were obtained on a solid T-2024 aluminum CEV model with a polycarbonate apex cover designed and fabricated at the Langley Research Center. The model is scaled by a factor of $3.03 \%$ of full-scale, based on vehicle dimensions as of the publication date of this report, yielding a maximum model diameter of 6.0 inches. An exploded view of the model assembly is shown in Figure 3.

The model is designed to receive a standard 6-component force and moment balance at a $45^{\circ}$ angle relative to its axis of symmetry. This sting exit angle and location were chosen to align

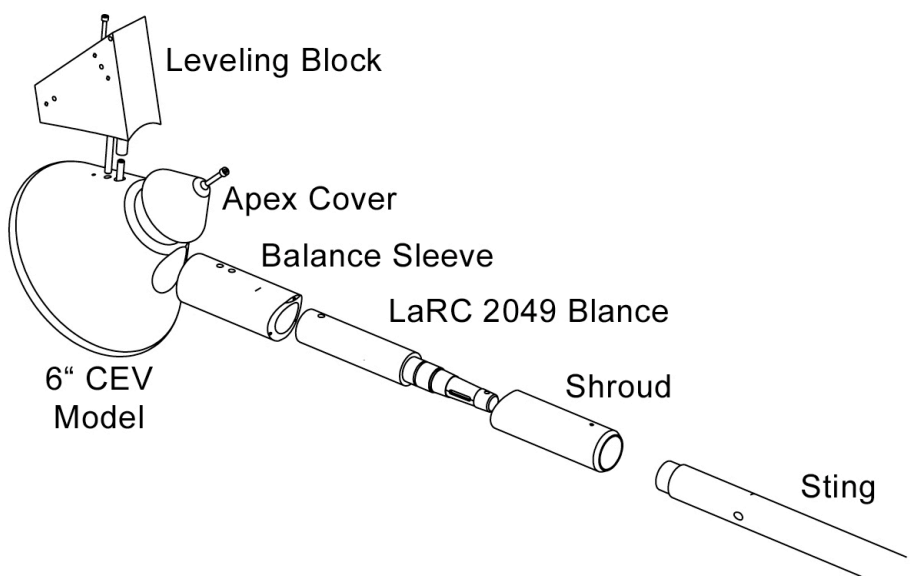

Figure 3. Exploded View of 3.03\% CEV Model, 2049 Balance, and 350-17B Sting Assembly for LaRC UPWT Testing. the sting with the wake flow over the Mach and angle-of-attack range to be tested in order to minimize sting interference effects. ${ }^{4}$ Sting size, orientation, and location were designed to match preliminary design drawings of a force-and-moment/pressure model to be tested at NASA Ames. The $3.03 \%$-scale model was designed to receive either of two cylindrical sleeves, fabricated from Nitronic-60, with precision fit internal bores for two LaRC force and moment balances, the LaRC 2049 and the LaRC 2008. The

sting used for testing, designated LaRC $350-17 \mathrm{~B}$, has a 1 -inch diameter and is fabricated from Vascomax 350. Balance cables are routed internal to the sting

and base pressure tubing is routed externally, fixed securely to the sting with fiberglass tape. A non-metric shroud, attached to the sting with approximately $0.1 \mathrm{in}$. clearance between it and the base of the model, was used to shield the aft end of the balance from flow and associated elevated heating. Model orientation in the wind tunnel was set via a leveling block and calibrated angular measurement system (AMS) package. Pre-test installation photographs are shown in Figure 4. 

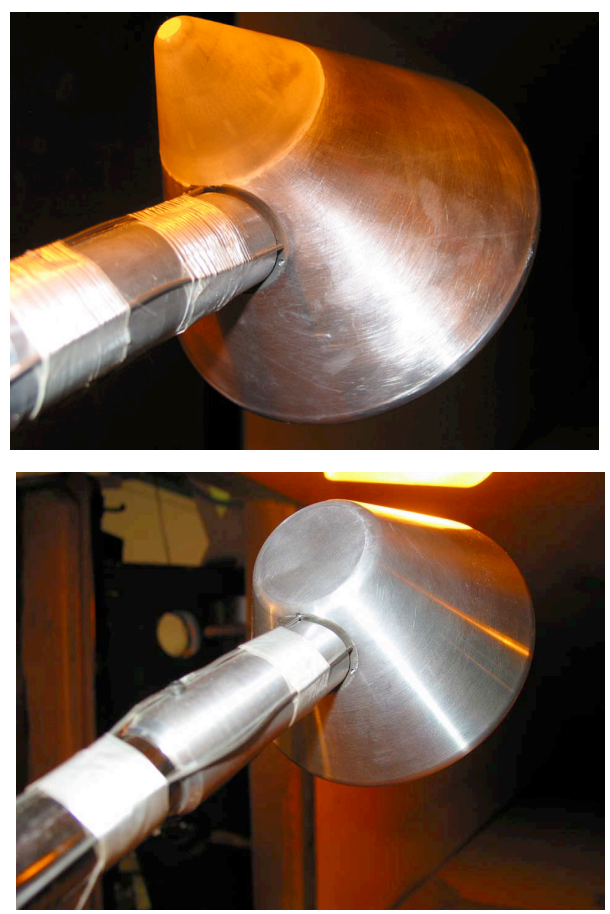

Figure 4. Installation photographs of the $3.03 \%$-scale CEV model, with and without apex cover, in the LaRC UPWT.
The outer mold lines of the aerodynamic model were checked (post-test) against model geometry files by Langley's Surface Verification Laboratory. The $\mathrm{x}, \mathrm{y}, \mathrm{z}$-location of numerous surface contour points were measured using discrete point techniques to characterize surface coordinate fidelity. The vast majority ( $>>95 \%)$ of points were found to be within the specified machining tolerance of \pm 0.005 in., with no point exceeding $0.0075 \mathrm{in}$. deviation from ideal contours. These surface measurements were also used to verify balance bore alignment and correct balance electrical center (i.e. center of gravity) location for accurate calculation of model attitude and moment transfer distances.

Pressure: All experimental static pressure data were obtained on a two-piece aluminum CEV model designed and fabricated at the Langley Research Center. Similar to the force and moment model, the pressure model is scaled by a factor of $3.03 \%$ of full-scale yielding a model maximum diameter of 6.0 inches. The outer-mold-line of the pressure model is identical to the aerodynamic model described in the preceding section, but not tested with an apex cover. The model, shown in Figure 5, is designed to receive a specially-built 1-inch diameter Vascomax 300 sting pinned to the model at a 45-degree angle relative to its axis of symmetry. This sting exit angle and location were identical to those of the CEV force and moment model described in the preceding section.

Figure 6 shows three schematic views of the static pressure tap lay-out in the $3.03 \%$-scale pressure model. The 81 taps in the $3.03 \%$ model are a subset of the 153 taps (shown with numerical designations in the schematic in Figure 6) on the 7.66\%-scale model tested at NASA Ames. The static taps are arranged in three radial rows and two circumferential rows, with the densest tap concentration on the shoulder in the area of highest curvature and highest expected pressure gradients. Pressure tubing leading from surface orifices had an inside-to-outside diameter ratio (I.D./O.D.) of 0.020 in./0.040 in. Due to the small internal volume of the model, no pressure instrumentation could be contained within the model body cavity. Thus the pressure tubing from each orifice was routed through the sting and the tunnel strut to external ESP modules to be described in subsequent sections.

The outer mold lines of the pressure model were checked (post-test) against model geometry files by Langley's Surface Verification Laboratory. The $\mathrm{x}, \mathrm{y}, \mathrm{z}$-location of numerous surface contour points were measured using discrete point techniques to characterize surface coordinate fidelity. All measured points were found to be within the specified machining tolerance of \pm 0.005 in., with more than $90 \%$ within 0.0025 in. deviation from ideal contours.

\section{$\underline{\text { Test Techniques and Instrumentation }}$}

Given the UPWT facility capabilities described in the preceding section, five different experimental techniques were used synergistically to obtain data on the two $3.03 \%$ scale CEV models to support development of the $\mathrm{CEV}$ aerodynamic database.

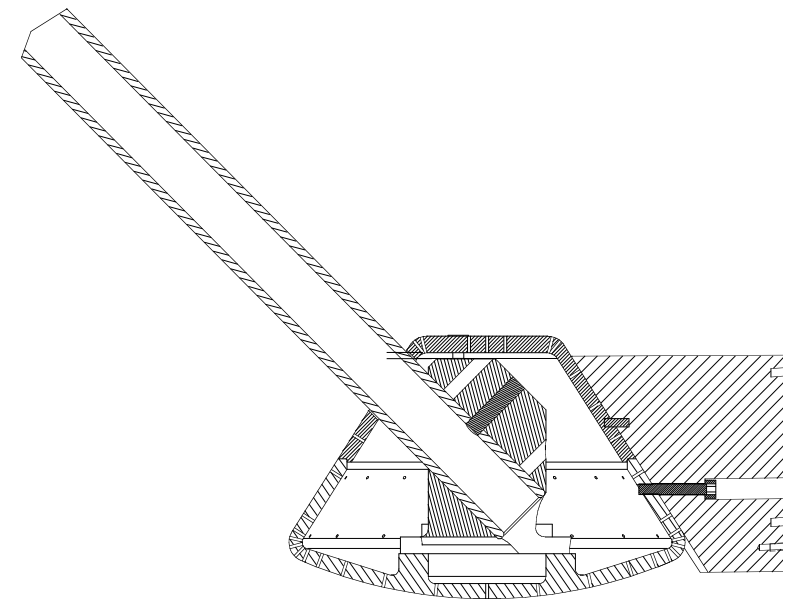

Figure 5. Design schematic of the 3.03\%-scale CEV static pressure model. 

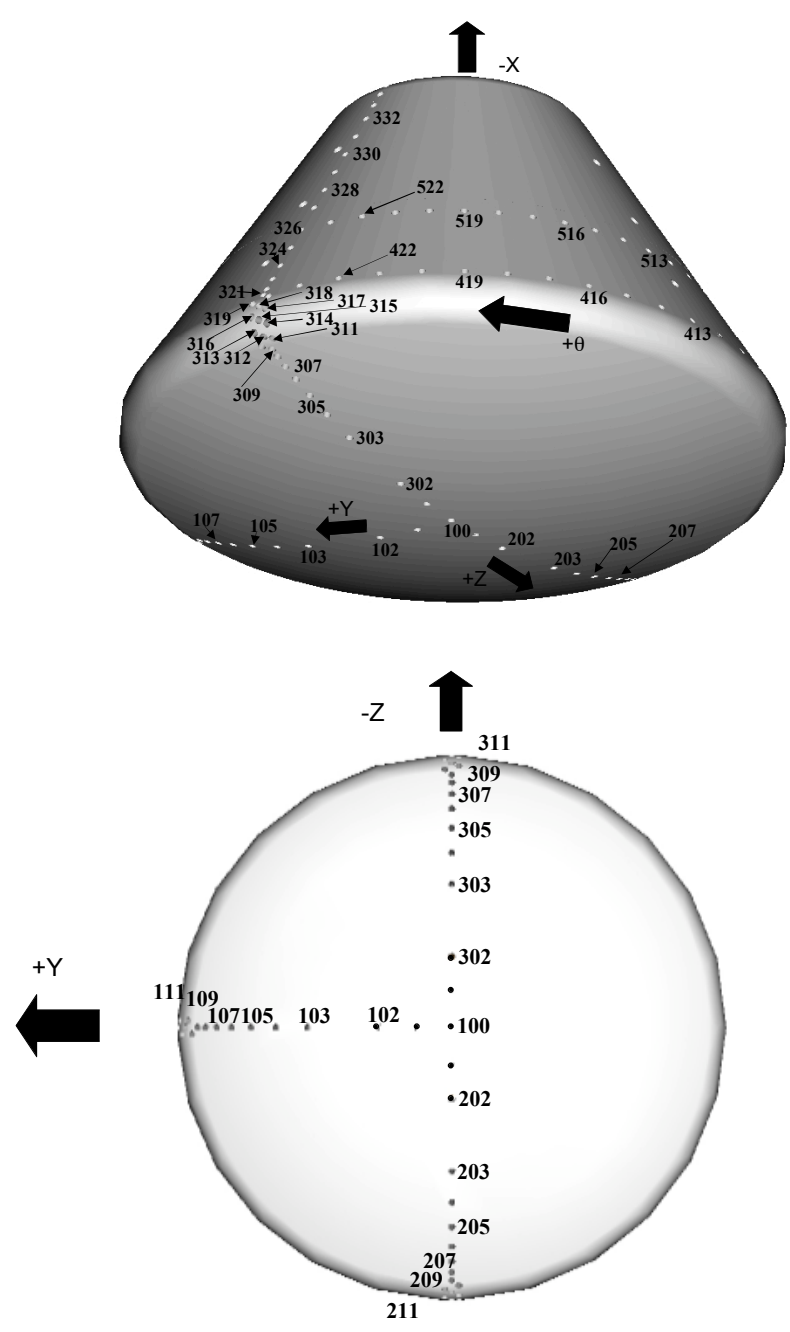

Figure 6. Three schematic views of pressure orifice layout on $3.03 \%$-scale CEV model.
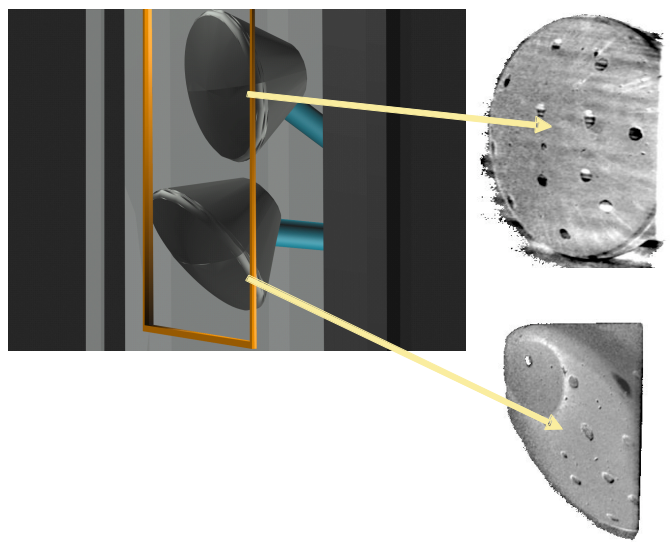

Figure 7. Virtual rendering of CEV capsule at minimum and maximum angles of attack and mirror in the UPWT.

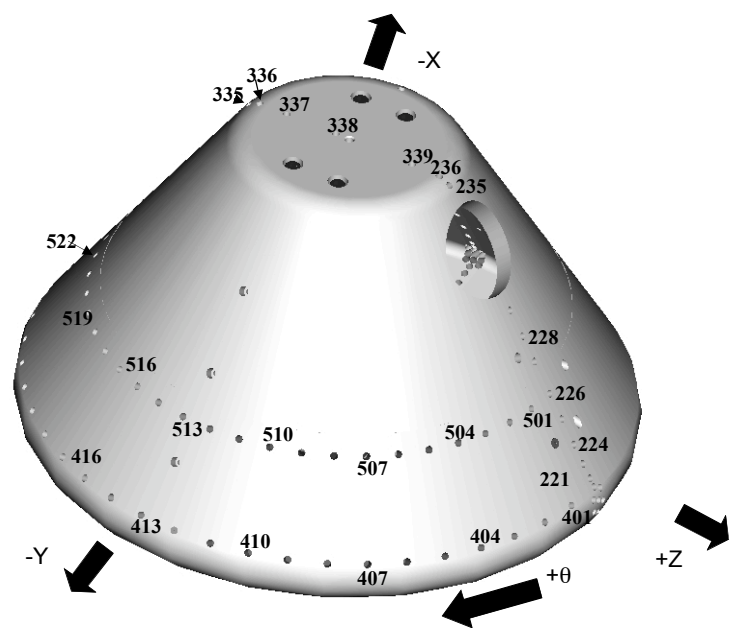

\section{(1) Virtual Diagnostics Interface (ViDI)}

The Virtual Diagnostics Interface $(V i D I)^{5}$ is comprised of a series of inter-related tools that are used by researchers to facilitate pre-test planning as well as real-time and post-test data visualization. The common thread throughout the ViDI applications is the use of an interactive, three-dimensional virtual environment containing accurately-scaled representations of the experimental facility and test articles. For the CEV test program in LaRC UPWT, use of ViDI simulation capabilities enabled efficient determination of the feasibility of optical-based experimental tools and facilitated optimized installation of test articles for synergistic use of test techniques.

One of the key aspects of ViDI is its pre-test simulation capability, enabling an experiment to be executed first in a virtual environment. Figure 7 depicts an optical simulation of the $3.03 \%$-scale CEV model installed in the UPWT. To obtain Temperature Sensitive Paint (TSP) images of the model, a mirror had to be attached to the side of one of the large slats on the side of the wind tunnel test section door. The image was

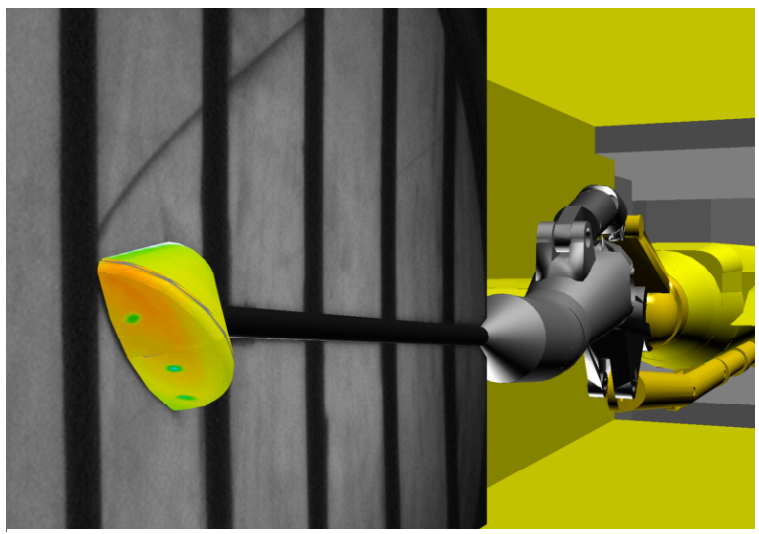

Figure 8. Rendering combining IR surface temperature data and Schlieren flow field image place in the virtual environment. 
simulated by creating ray-traced renderings of the reflections off of a virtual mirror modeled in the scene. A variety of camera angles and mirror placements were simulated until an optimum solution was determined. The pre-test simulation verified that the existing mirror (orange rectangle in Figure 7) provided adequate view angles of the heat shield throughout the range of angles of attack to be tested. ViDI was also used in a post-test capacity to unite data from different instruments and tests. Figure 8 shows the CEV virtual model in the UPWT with Infrared (IR) thermography data mapped onto its surface and Schlieren imagery obtained during a subsequent test mapped onto the surrounding flow field. Companion computational results could also be incorporated into the visualization in order to compare and analyze the flow features of interest.

\section{(2) Temperature Sensitive Paint Thermography}

Temperature sensitive paint (TSP) thermography is a well-proven, non-intrusive technique for measuring surface temperatures and has been applied to investigate aerodynamic heating, and detect flow transition, separation, and reattachment. ${ }^{6}$ TSP is analogous to pressure sensitive paint (PSP) in that it is typically constructed by dispersing luminescent probe species (luminophores) within a suitable polymeric binders or paints. Whereas PSP uses an oxygen permeable binder to measure luminescence decrease with increasing oxygen condition, TSP binders are generally constructed using an oxygen impermeable binder. Thus the luminescence change is directly related to only changes in temperature, with increasing temperature resulting in a decrease in luminescence.

TSP measurements require a paint formulation, illumination (i.e. excitation) source(s), scientific-grade CCD camera(s), and optical filters for spectral discrimination between the excitation and emission light. Images are captured by a PC, and image processing is generally performed offline on a separate platform. For transition detection on the CEV model, a powder coat layer was first deposited onto the model surface to ensure that only the surface temperatures affected the luminescence. This coating was on the order of several microns thick and was deposited using traditional electrostatic-coating methods (described in more detail in the following section). The TSP coating was then applied using standard spray-coating techniques, resulting in a paint layer that is $1-2$ microns thick $(\approx 0.0001$ in. $)$. The instrumentation

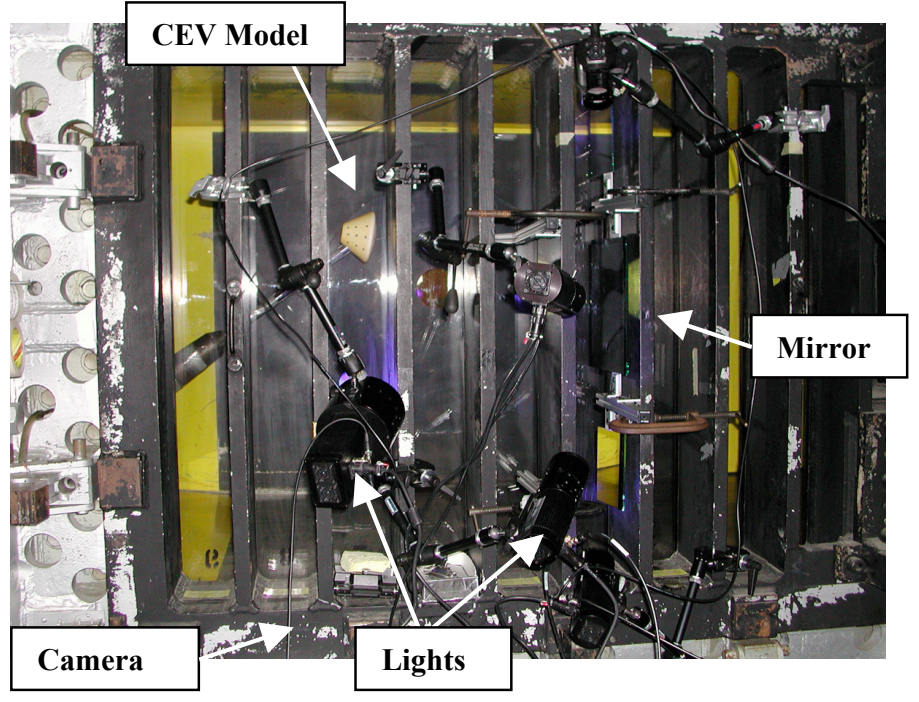

Figure 9. Instrumentation layout for TSP acquisition on 3.03\%-scale CEV model in LaRC UPWT. set-up is depicted in Figure 9.

Visualization of the transition location was accomplished by adding heat pulses to the tunnel. First a reference image was collected with the tunnel running at condition. Next a heat pulse was added to increase the model surface temperature as rapidly as possible ( $\sim 1$ degree per second temperature increase). To visualize the transition location, the reference image is ratioed with the images collected during the heat pulse, resulting in an image where higher values relate to higher temperatures.

\section{(3) Infrared Thermography}

Infrared thermography is a non-intrusive video-based, radiometric measurement technique capable of obtaining real-time global surface temperature data based on blackbody radiation theory. ${ }^{7}$ Infrared thermography is particularly useful in remotely detecting transitional flow on a test article. The variation of the local heat-transfer coefficient between the laminar and turbulent flow regions will induce small surface temperature gradients that can be detected by an infrared camera. In order to fully exploit this measurement technique, it is important to optimize specific radiometric and thermophysical properties of the test article so the best possible infrared signature can be obtained for a given set of conditions. Ideally the surface should possess a high emissivity (effectiveness of a real object is at absorbing/emitting radiation compared

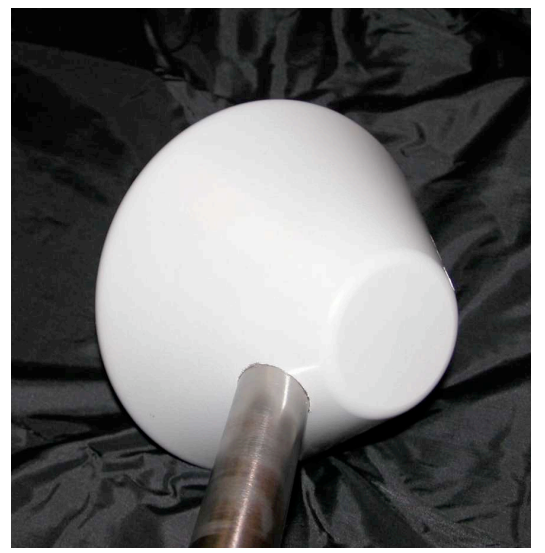

Figure 10. 3.03\%-scale CEV model with powder coating. 
to an ideal "blackbody"), low thermal conductivity and low specific heat capacity. For an opaque surface, increasing its emissivity will increase the radiance (signal) and subsequently reduce the reflectivity (noise). A low thermal conductivity surface is beneficial because it will minimize conduction losses into the structure, retaining the surface temperature gradient for a longer period of time and improving the signal/noise ratio. Similarly, minimizing the surface specific-heat capacity is also desirable since there will be a larger detectable surface temperature rise for a given heat input.

In order to get the best possible thermal signatures from this model, a high emittance, low thermal conductivity and low specific heat powder coating was applied to the model surface. A smooth matte-finish gray polyesterepoxy hybrid polymer powder coating was electrostatically applied in a 0.004-in thick layer over the model surface. The CEV model with powder coating applied is shown in Figure 10.

(4) Force and Moment Measurements:

Aerodynamic forces and moments were measured using a 6-component strain-gage balance, a standard experimental instrument for generating aerodynamic data. The primary balance for this test program was the LaRC 2049, and the secondary balance was the LaRC 2008. To achieve the highest Reynolds number possible (to match CEV data from NASA Ames), 1.5 million based on model diameter ( 3 million per foot unit Reynolds number), the 2049 balance was run at a maximum overload condition of $135 \%$ of its rated normal force. Pre-test overload approval was granted based on in-tunnel check loads and a stress analysis using the expected maximum loads on all six components. Extensive post-test loadings were conducted in a balance calibration facility that provided verification that the 2049 calibration matrix was valid over the extended load range.

All aerodynamic data were taken in a pitch-pause mode and corrected real-time for support system deflection under loading. Flow angularity is typically measured for each test entry using $\mathrm{C}_{\mathrm{N}}$ values for upright and inverted runs at angles of attack near zero. Because these values are small for a blunt body-dominated by axial force at low angles of attack-these data would not provide sufficient resolution to characterize flow angularity. Thus data were corrected post-test for flow angularity based on existing facility calibrations where flow angularity is a function of tunnel freestream flow conditions, predominantly Mach number. Three static pressure measurements at the stingbody interface were made externally using an off-board electronically scanned pressure (ESP) module, but no corrections were made to the data. Base pressures are small and for this model with no sting cavity, traditional base and cavity corrections would cancel each other. Wind-off balance readings were monitored before and after each run, and balance components were monitored during the tunnel run for drift caused by thermal gradients across the balance gages. Hysteresis checks were done by comparing ascending and descending pitch sweep data, and withintest repeatability was addressed by doing selected repeat runs through the test matrix. Observed variations were compared to quoted balance accuracies for all six components based on the $\pm 95 \%$ confidence level from balance calibration reports. Balance loads and $\pm 2 \square$ uncertainties for representative flow conditions are also shown in Table 3. It should be noted that the aforementioned balance accuracies represent only the uncertainties associated with the balance itself. This would be a measure of the overall uncertainty on the wind tunnel measurements only in the absence of all other variations. Repeat runs were acquired throughout the test matrix to provide estimates of withintest repeatability. Aerodynamic data obtained from differently scaled models in multiple wind tunnel facilities will be statistically analyzed to obtain the most rigorous estimate of overall uncertainty for input into the aerodynamic database.

Table 3. Longitudinal loads and component accuracies for the LaRC balance 2049.

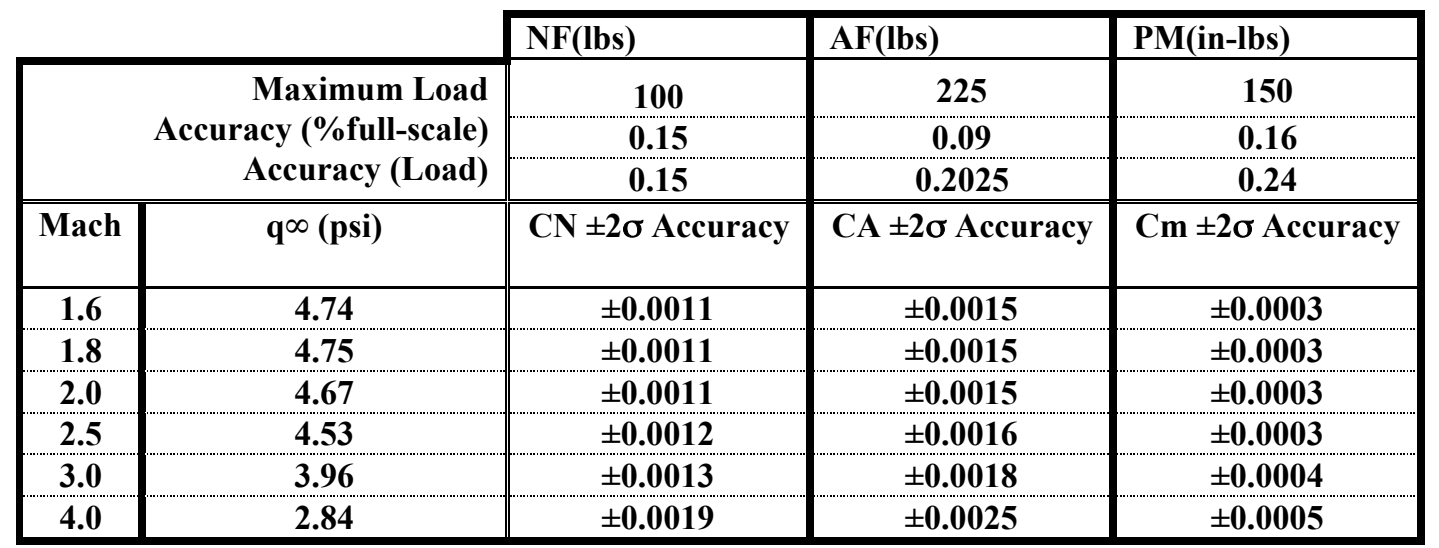


(5) Static Pressure Measurements: Surface pressure measurements, as well as limited base and cavity pressures measurements that accompanied the force tests, were made using commercially available electronically scanned pressure (ESP) modules. Miniature ESP electronic pressure scanners are differential pressure measurement units consisting of an array of silicon piezoresistive pressure sensors, one for each pressure port. ESP modules are designed and calibrated to measure over a given range of pressures. Those used for this study were rated for a nominal maximum pressure of 15 psid to capture the range of higher pressures expected on the windward heat shield and the lower pressures expected on the conical aft-body. The differential ESP modules were used as absolute gages by evacuating the reference side of the modules using a common vacuum source. As mentioned previously, given the small scale of the 3.03\%-scale model, ESP modules could not be mounted internally to the model, as was done in larger scale models. Modules were located aft of the tunnel support strut just outside the test section to minimize tubing length and corresponding settling times.

Pressure tubing leading from surface orifices had an inside-to-outside diameter ratio (I.D./O.D.) of 0.020 in./0.040 in. and exited the model directly through the 1-inch diameter sting and out the back of the sting coupling in a protective casing with a total length of approximately 10 feet. These tubes were then directly connected to the two 15 psi ESP modules described above.

Static pressure data were taken after allowing the model to sit at each angle of attack for 30 seconds. (Pressure settling times were verified by generating unchanged results with model dwell times of 15 and 30 seconds.) Pressure readings were collected at 30 frames per second over a 2 second interval and averaged to yield each data point. Several pressures on the model were cross-checked with in-situ facility pressure instrumentation (5 psia modules made by Druck, Inc.) over the course of the test entry, and data compared within manufactured-specified uncertainty of $\pm 0.1 \%$ of full-scale module rating.

\section{$\underline{\text { Test Plan }}$}

Test Summary: The test program described herein represents data from CEV Tests 1-CA, 3-CA, and 7-CA. A summary of test information is presented in Table 4.

Table 4. Summary of CEV Testing Program in Langley UPWT.

\begin{tabular}{|l|l|l|l|l|l|}
\hline Test & Test Purpose & Test Techniques & Occupancy Dates & UPWT I & UPWT II \\
\hline CEV 1-CA & Transition Studies & ViDI, TSP, IR & $12 / 13 / 2005-12 / 16 / 06$ & Test 1944 & Test 1781 \\
\hline CEV 3-CA & Static Aerodynamics & ViDI, Force and Moment & $1 / 27 / 06-2 / 6 / 06$ & Test 1948 & Test 1785 \\
\hline CEV 7-CA & Static Aerodynamics & ViDI, Force and Moment, & $3 / 27 / 06-4 / 10 / 06$ & Test 1952 & Test 1789 \\
& Static Pressures & Pressure & & Test 1954 & Test 1791 \\
\hline
\end{tabular}

Test Parameters: TSP, IR, force and moment, and static pressure data were obtained on the $3.03 \%$-scale CEV configuration over the following nominal range of attitude, flow, and configuration parameters:

Attitude Parameters

- Angles of attack: $140^{\circ}, 142^{\circ}, 144^{\circ}, 146^{\circ}, 148^{\circ}, 150^{\circ}, 152^{\circ}, 154^{\circ}, 156^{\circ}, 158^{\circ}, 160^{\circ}, 162^{\circ}, 164^{\circ}, 166^{\circ}, 168^{\circ}, 170^{\circ}$.

- Angle of sideslip: $0^{\circ}$ for all runs

- Angle of roll: $0^{\circ}$ for all runs.

The CEV aerodynamic coordinate system is shown in Figure 11. Apex forward is 0 deg angle of attack; heat shield forward is 180 deg angle of attack.

Flow Field Parameters

- Mach numbers: 1.6, 1.8, 2.0, 2.5, 3.0, 4.0

- Unit Reynolds numbers (per ft): $1 \times 10^{6}, 2 \times 10^{6}, 3 \times 10^{6}$.

Configuration Parameters

- Outer-mold-line configurations: Apex cover on and off

- Surface roughness configurations: Clean, LaRC grit pattern, ARC trip dot pattern, full grit. 


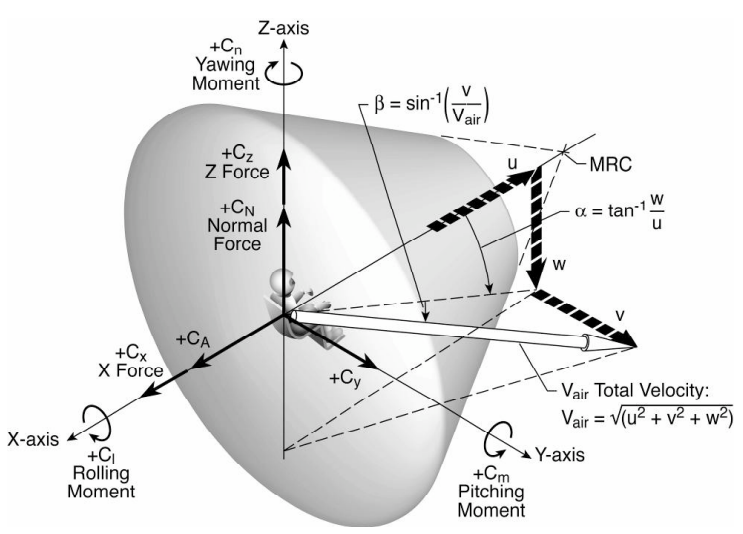

Figure 11. Aerodynamic coordinate system for the CEV command module configuration

As experimental results will show, both TSP and IR thermography temperature maps showed surface flow to be laminar on the heat shield for $\operatorname{Re}_{\mathrm{d}} \leq 1.5 \times 10^{6}$ over the Mach number range 1.6 to 4 . Thus the CEV configuration was tested with a grit pattern applied to promote transition. The grit was sized using the GRITTS3 program at the LaRC UPWT. This program assumes a standard flat-plate-type boundary layer profile, calculating the critical Reynolds number for transition, the boundary layer thickness, and the corresponding three-dimensional roughness height and location necessary to trip the boundary layer for a given flow condition (based on the work of Braslow, et $a l^{8}{ }^{8}$ ). However, some approximations had to be made to adapt this program to the current blunt body surface flow. The modeling assumption for sizing grit for the windward face was that the flat plate boundary layer model could be applied to flow emanating radially outward from the stagnation region, neglecting any pressure gradient effects due to surface curvature. The post-normal shock properties for the given range of supersonic Mach numbers were thought to be the best physical approximation for the freestream inputs. Tables 5 and 6 list the post-shock properties and corresponding boundary layer thickness approximation, roughness height, and resultant grit size (for selected surface flow running lengths where the critical Reynolds number is achieved).

Table 5. Freestream and post-shock flow conditions for LaRC UPWT.

\begin{tabular}{|l|l|l|l|l|l|l|}
\hline $\mathrm{M}_{1}$ & $\mathrm{P}_{\mathrm{T} 1}\left(\mathrm{Re}=3 \times 10^{6}\right), \mathrm{psf}$ & $\mathrm{T}_{\mathrm{T} 1},{ }^{\circ} \mathrm{F}$ & $\mathrm{P}_{\mathrm{T} 2} / \mathrm{P}_{\mathrm{T} 1}$ & $\mathrm{M}_{2}$ & $\mathrm{P}_{\mathrm{T} 2}, \mathrm{psf}$ & $\mathrm{T}_{\mathrm{T} 2},{ }^{\circ} \mathrm{F}$ \\
\hline 1.6 & 1618 & 125 & 0.8952 & 0.6684 & 1448.4 & 125 \\
\hline 1.8 & 1731 & 125 & 0.8127 & 0.6170 & 1407 & 125 \\
\hline 2.0 & 1880 & 125 & 0.7209 & 0.5774 & 1355.3 & 125 \\
\hline 2.5 & 2548 & 150 & 0.4990 & 0.5130 & 1271.5 & 150 \\
\hline 3.0 & 3324 & 150 & 0.3283 & 0.4752 & 1091.3 & 150 \\
\hline 4.0 & 5547 & 150 & 0.1388 & 0.4350 & 769.9 & 150 \\
\hline
\end{tabular}

Table 6. Results from GRITTS3 for LaRC UPWT flow conditions.

\begin{tabular}{|l|l|l|l|l|l|}
\hline $\mathrm{M}_{1}$ & $\mathrm{Re}_{1} / \mathrm{ft} \times 10^{6}$ & $\mathrm{M}_{2}$ & $\mathrm{x}$, in & $\mathrm{K}$, in & Grit Number \\
\hline 1.6 & 3.0 & 0.6684 & .75 & .00477 & 120 \\
\hline 1.8 & 3.0 & 0.6170 & .75 & .00503 & 110 \\
\hline 2.0 & 3.0 & 0.5774 & .75 & .00533 & 100 \\
\hline 2.5 & 3.0 & 0.5130 & 1.5 & .00726 & 80 \\
\hline 3.0 & 3.0 & 0.4752 & 1.5 & .00850 & 70 \\
\hline 4.0 & 3.0 & 0.4350 & 1.5 & .01173 & 60 \\
\hline
\end{tabular}

Based on these calculations, an oval pattern of grit was applied to the CEV force model (run without a force balance for transition studies) as shown in Figure 12. The lower portion of the oval was based on a semi-circle of grit centered at 2.25" above the model center, an average value of the stagnation point for the angle of attack range tested. The top portion was an elliptical shape necessary to keep the grit ring on the heat-shield face. Each Mach number and angle of attack would yield a different optimized grit pattern and grit size. Thus the grit pattern used for the transition tests represented a compromise, sized conservatively in an attempt to trip all Mach numbers. Randomly-applied Number 90 Grit was used in Test Section 1 (Mach Numbers 1.6, and 2.0) and Number 50 grit was used in Test Section 2 (Mach numbers 2.5, 3.0, and 4.0). This grit pattern was then duplicated on the CEV force model mounted on a force balance to generate aerodynamic data. A similar methodology was used for sizing grit for a larger-scale model to be tested in the Ames 11-ft and 9x7-ft tunnels. Standard procedures for these facilities use trip dots (as opposed to grit particles) applied prior to application of TSP/PSP coatings. Thus the trip dot configuration designed for the Ames model was tested in the LaRC UPWT for comparison. Because trip dot 
tape can only be applied in straight lines, the circular trip ring was approximated by an octagonal shape, shown in Figure 12.

Since there was not sufficient time to look at multiple grit configurations, the baseline CEV model, without apex cover, was also tested with random grit applied over the entire surface of the model, shown in Figure 12. It was hoped that acquiring data with the model clean, with the LaRC grit ring, and fully gritted would produce a comparison of aerodynamic and pressure data with the widest possible variation of surface flow conditions.
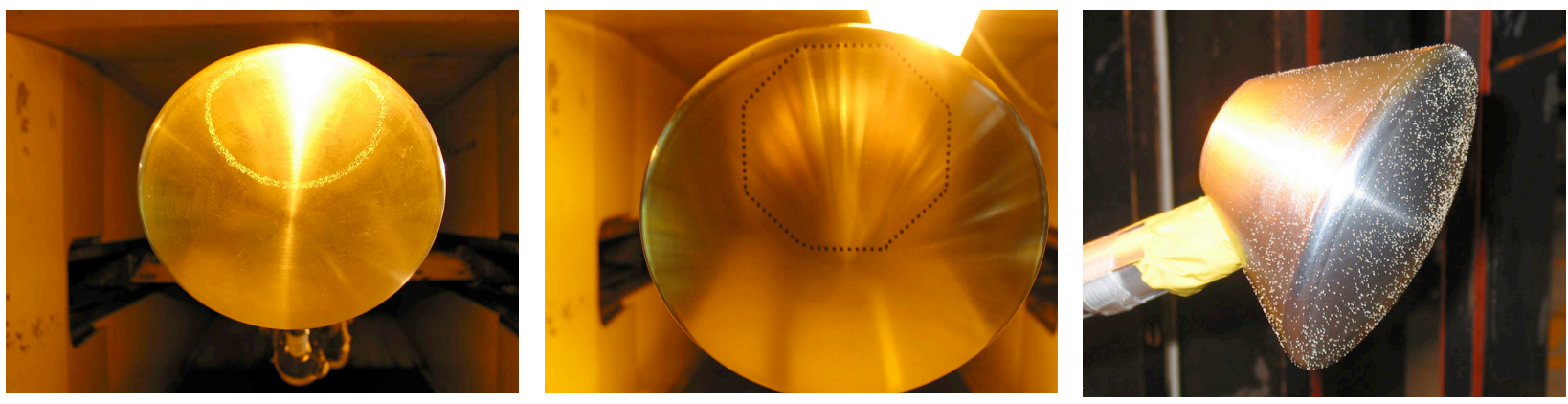

Figure 12.3.03\% CEV model with LaRC grit ring, ARC trip dot hexagon, and full grit.

\section{Results}

Given the scope of the test program described above, the complete data sets generated via TSP, IR, force and moment, and surface pressure techniques cannot be presented herein. Thus the data presented in this report will highlight key data and significant trends relevant to static aerodynamic characteristics of the current CEV configuration. More detailed data releases are found in CEV program test reports for Tests $1-\mathrm{CA}^{9}, 3-\mathrm{CA}^{10}$, and 7CA. $^{11}$

\section{$\underline{\text { Transition Studies }}$}

Infrared thermography and temperature sensitive paint thermography, complimented by virtual diagnostic simulation tools, were the test techniques used to gain insight into flow transition characteristics on the CEV configuration in the LaRC Unitary Plan Wind Tunnel. The three main objectives of the transition studies were (1) to determine if flow on the heat shield is naturally laminar or turbulent for $\operatorname{Re}_{\mathrm{d}} \leq 1.5 \times 10^{6}$ (2049 balance load limit), (2) to use boundary layer trips if necessary to force transition on the heat shield for $\operatorname{Re}_{\mathrm{d}} \leq 1.5 \times 10^{6}$, and (3) to determine if flow on the heat shield is naturally laminar or turbulent for $\operatorname{Re}_{\mathrm{d}} \leq 3.5 \times 10^{6}$ (UPWT facility operating limit).

Due to balance load limitations, the CEV force and moment model with the 2049 balance installed could only be run up to a maximum Reynolds number of $\mathrm{Re}_{\mathrm{d}}=1.5 \times 10^{6}$. Flight Reynolds numbers for the CEV at supersonic conditions are estimated to be in the range of $13-21 \times 10^{6}$, and the vehicle boundary layer is expected to be turbulent. At such low Reynolds numbers in the wind tunnel it is often necessary to trip a boundary layer to force transition in order to obtain both laminar and turbulent data for comparison. To satisfy the first objective above, IR and TSP were first used to characterize the natural boundary layer on the CEV model in the UPWT. Figure 13 shows IR images of the CEV force model in the UPWT at $\mathrm{M}=1.6, \mathrm{M}=2.0$, and $\mathrm{M}=2.5$ for angles of attack of $170^{\circ}, 156^{\circ}$, and $140^{\circ}$ (angles chosen to characterize full angle of attack range). Note that these images are only qualitative and color scales differ slightly to maximize the temperature range of each image. Vertical striations on the heat shield correspond to a reflection of bars of the wind tunnel window and dots are metallic markers used for TSP measurements. What can be observed from these images is primarily where temperature gradients occur on the heat shield. Temperatures are in general more uniform with increasing angle of attack as the stagnation points are closer to the center and favorable pressure gradients on the face are not as large. At $\square=140^{\circ}$ all Mach numbers show high heating at the stagnation point (just below the shoulder region) and then decreasing temperatures as the flow traverses down the heat shield in a favorable pressure gradient and around the opposite shoulder. If transition were to occur some distance away from the stagnation point, an increase in temperatures would be seen via IR thermography images from the corresponding increase in turbulent heating. Images in Figure 13 indicate that for 


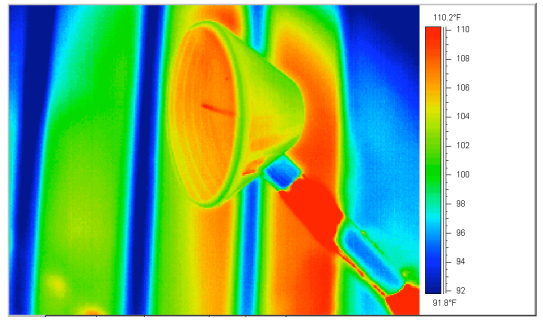

(a) $\mathrm{M}=1.6, \square=170^{\circ}$

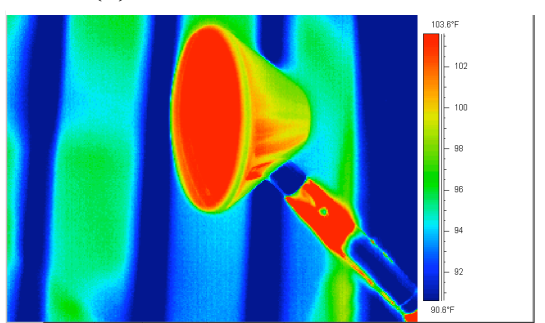

(d) $M=2.0, \square=170^{\circ}$

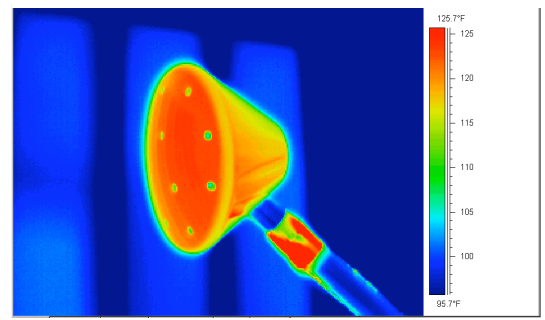

(g) $\mathrm{M}=2.5, \square=170^{\circ}$

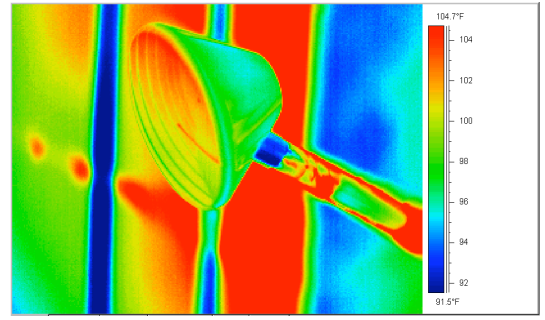

(b) $\mathrm{M}=1.6, \square=156^{\circ}$

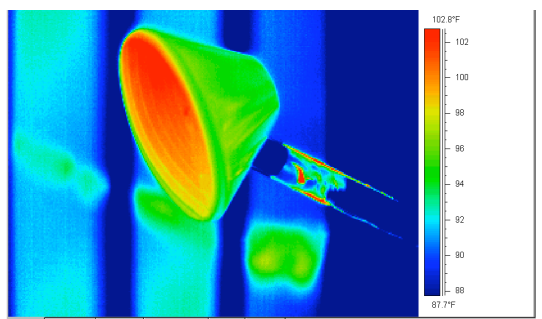

(e) $\mathrm{M}=\mathbf{2 . 0}, \square=156^{\circ}$

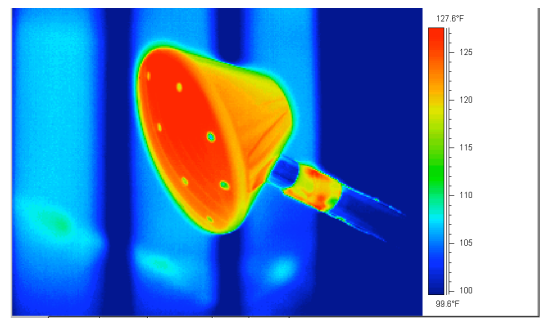

(h) $\mathrm{M}=2.5, \square=156^{\circ}$

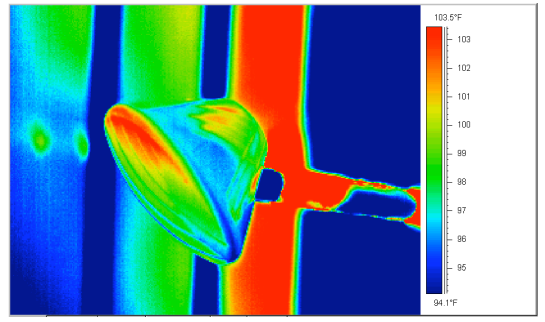

(c) $\mathrm{M}=1.6, \square=140^{\circ}$

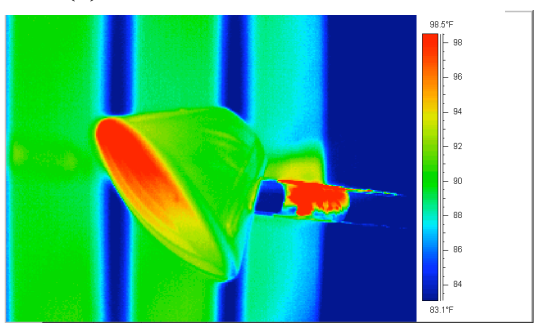

(f) $M=2.0, \square=140^{\circ}$

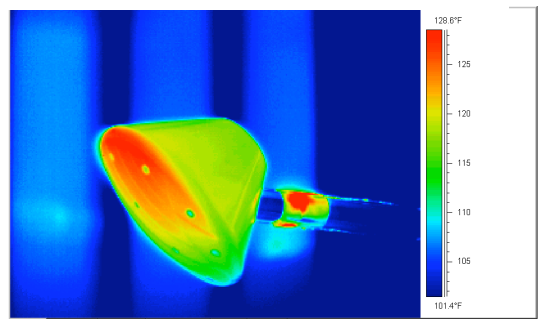

(i) $\mathrm{M}=2.5, \square=140^{\circ}$

Figures 13. Infrared thermography qualitative temperature images of $C E V$ for $\operatorname{Re}_{\mathrm{d}}=1.5 \times 10^{6}$.

the range of Mach and Reynolds number available for aerodynamic testing, conditions on the heat shield face are laminar. TSP images, not presented here, showed the same results.

The second objective in these transition studies was to use boundary layer trips to force transition on the heat shield for $\operatorname{Re}_{\mathrm{d}} \leq 1.5 \times 10^{6}$, verifying this via IR and TSP techniques. The sizing and location of the grit ring was

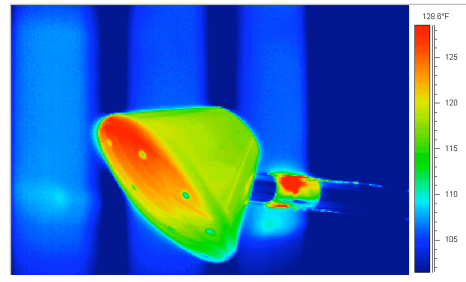

(a) No Grit, $\operatorname{Re}_{\mathrm{d}}=1.5 \times 10^{6}$
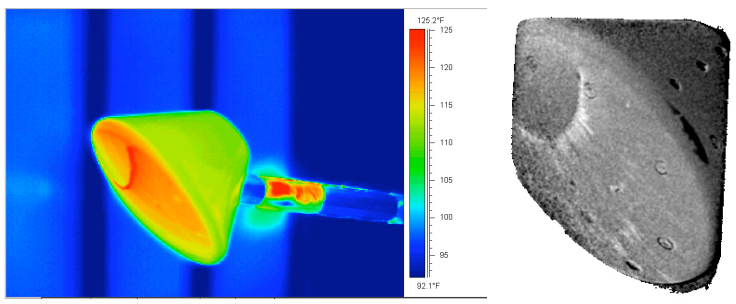

(c) LaRC Grit, $\operatorname{Re}_{\mathrm{d}}=1.5 \times 10^{6}$
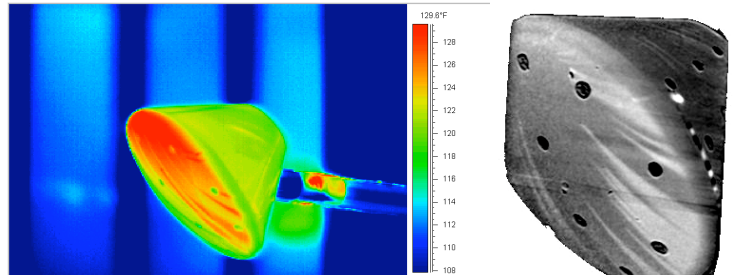

(b) No Grit, $R_{\mathrm{d}}=2.5 \times 10^{6}$
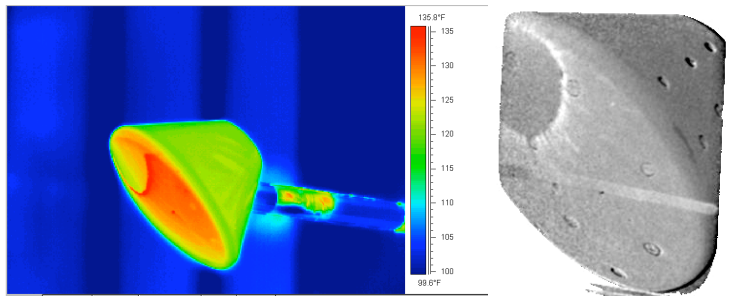

(d) LaRC Grit, $\operatorname{Re}_{\mathrm{d}}=2.5 \times 10^{6}$

Figure 14. IR and TSP qualitative temperature images of the CEV model with no grit and with LaRC grit ring at $\square=140^{\circ}$ and $M=1.6$. 
described earlier in this report. Figure 14 shows both IR and TSP images for the CEV model with and without transition grit at $M=1.6$. Figures $14(\mathrm{a})$ and 14 (c) show the clean and tripped model at $\mathrm{Re}_{\mathrm{d}}=1.5 \times 10^{6}$, the planned baseline for aerodynamic testing. While there is a well-defined increase in heating at the grit ring, it is not certain based on these results alone that this increase corresponds to turbulent flow. (Again note that scales are different among the images; e.g. the stagnation region is the same temperature between Figures 14(a) and 14(c), but shown cooler in Figure 14(c) because there are now hotter regions on the heat shield.) Figure 14(c) shows higher relative temperature on the lower shoulder compared with Figure 14(a), but with favorable pressure gradients for both conditions, it is again difficult to isolate temperature effects due to transition. In order to gain more insight into the images at $\operatorname{Re}_{\mathrm{d}}=1.5 \times 10^{6}$, Reynolds number was increased above the aerodynamic testing limit to $\operatorname{Re}_{\mathrm{d}}=2.5 \times 10^{6}$. Both IR and TSP images show evidence of the onset of natural transition via increased heating associated with welldefined turbulent wedges emanating some distance along the surface from the stagnation point (Fig. 14(b)). When the model is run at these same conditions with the grit ring applied, evidence of these turbulent wedges no longer appears (Fig 14(d)), indicating that the flow field has been globally affected at the grit strip and that transition has occurred for these conditions. It is comparison of Figures 14(c) and 14(d) that makes a strong case for transition in Figure 14(c) at the lower Reynolds number. (Higher Reynolds number data shown in the next section will further support this conclusion.) Thus gritting the model for the force and moment studies allowed generation of aerodynamic data with turbulent flow on the heat shield.

Although balance load limitations prevented running the aerodynamic model at Reynolds numbers higher than $\mathrm{Re}_{\mathrm{d}}=1.5 \times 10^{6}$ in the LaRC UPWT, knowledge of transition characteristics at higher Reynolds number testing would be applicable to CEV testing in the ARC UPWT. Figure 15 shows the TSP images at M=1.6 and $\square=140^{\circ}, 156^{\circ}$, and

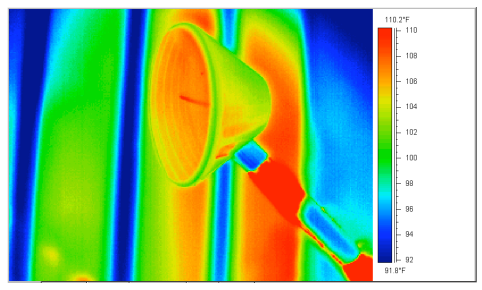

(a) $\operatorname{Re}_{\mathrm{d}}=1.5 \times 10^{6}, \square=170^{\circ}$

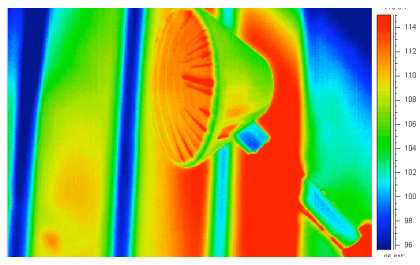

(d) $\operatorname{Re}_{\mathrm{d}}=2.5 \times 10^{6}, \square=170^{\circ}$

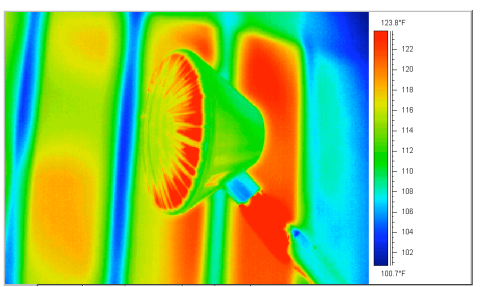

(g) $\operatorname{Re}_{\mathrm{d}}=3.5 \times 10^{6}, \square=170^{\circ}$

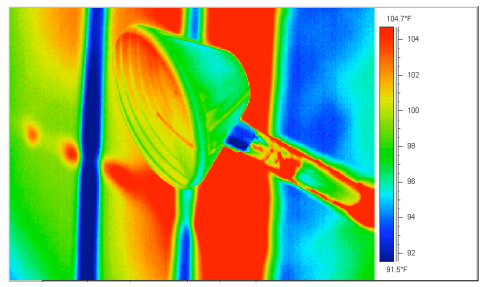

(b) $\operatorname{Re}_{\mathrm{d}}=1.5 \times 10^{6}, \square=156^{\circ}$

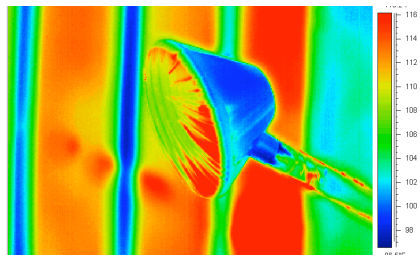

(e) $\operatorname{Re}_{\mathrm{d}}=2.5 \times 10^{6}, \square=156^{\circ}$

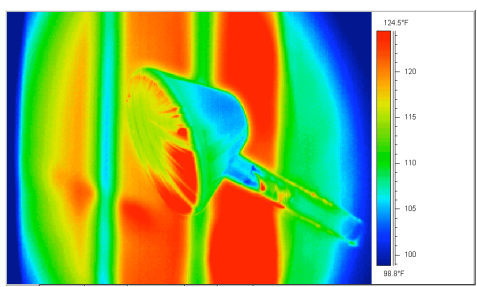

(h) $\operatorname{Re}_{\mathrm{d}}=3.5 \times 10^{6}, \square=156^{\circ}$

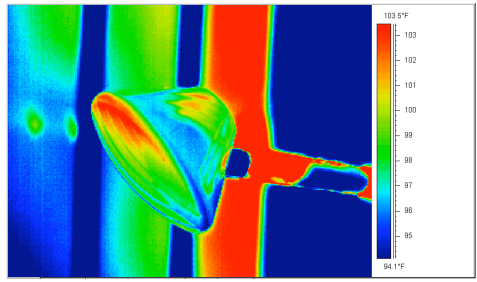

(c) $\operatorname{Re}_{\mathrm{d}}=1.5 \times 10^{6}, \square=140^{\circ}$

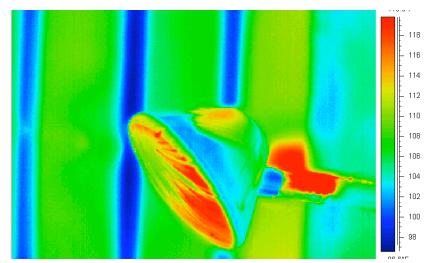

(f) $\operatorname{Re}_{\mathrm{d}}=2.5 \times 10^{6}, \square=140^{\circ}$

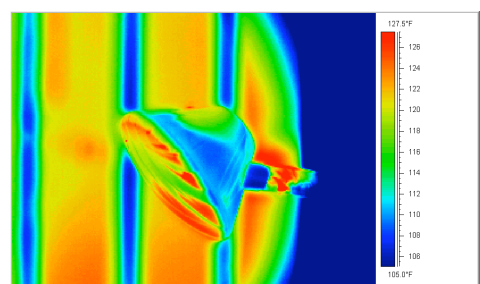

(i) $\operatorname{Re}_{\mathrm{d}}=3.5 \times 10^{6}, \square=140^{\circ}$

Figures 15. Infrared thermography qualitative temperature images of CEV for $M=1.6$.

$170^{\circ}$ at for Reynolds numbers $\operatorname{Re}_{\mathrm{d}}=1.5 \times 10^{6}, 2.5 \times 10^{6}$, and $3.5 \times 10^{6}$. Turbulent wedge heating signatures are seen at all three angles of attack for the two higher Reynolds numbers conditions (Figs. 15(d)-15(i)). These wedges appear to combine into a defined transition front at $\mathrm{Re}_{\mathrm{d}}=3.5 \times 10^{6}$ (Figs. 15(g)-15(i)). An important factor influencing "natural" transition is surface degradation. Many of the TSP and IR images show isolated "wedges" or "streaks" (e.g. Figs. 15(a), 15(b), 15(d)), which, at closer inspection of the images, emanate from a small damage point on the paint coat on the model due to particulates in the flow. Inspection of the model after running at the highest Reynolds number condition showed a large number of "pits" in the model's paint. Figure 16 presents IR and TSP 
images for the same test conditions $\left(\mathrm{M}=1.6, \mathrm{Re}_{\mathrm{d}}=1.5 \times 10^{6}\right)$ but before and after a set of high Reynolds number runs. Figures 16(a)-16(c) are images taken in runs early in the test program and show no evidence of natural transition, while Figures 16(d)-16(f) are images taken after significant surface degradation and show numerous turbulent wedges for all angles of attack. While these results compromise conclusions regarding "natural" transition on this configuration at higher Reynolds numbers, they do provide more support to the ability to trip the flow via surface roughness.

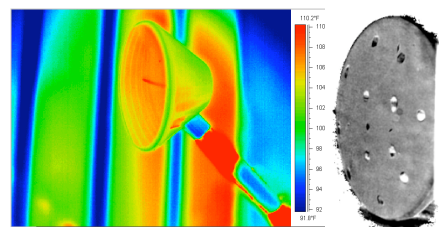

(a) "Early", $\square=170^{\circ}$

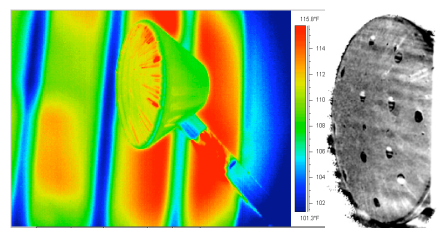

(d) "Damage", $\square=170^{\circ}$

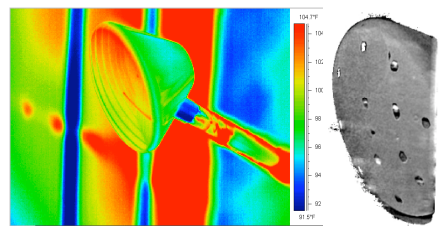

(b) "Early", $\square=156^{\circ}$

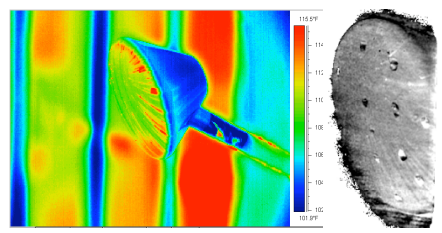

(e) "Damage", $\square=156^{\circ}$

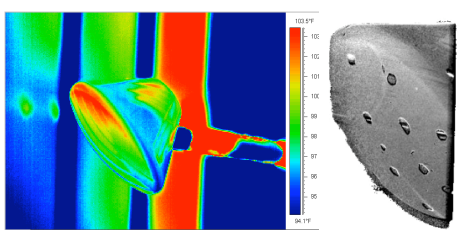

(c) "Early", $\square=140$ "

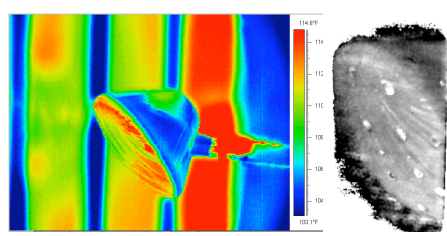

(f) "Damage", $\square=140^{\circ}$

Figure 16. IR and TSP qualitative temperature images of $C E V$ for $M=1.6, R_{d}=1.5 \times 10^{6}$.

\section{Aerodynamic Studies}

Figures 17 through 23 present longitudinal static aerodynamic data from LaRC UPWT Tests 1948, 1952, 1785, and 1789 with a 6-inch diameter CEV model. All flow field and configuration parameters are plotted as a function of model angle of attack. Symbols represent the discrete angles at which data were taken. Curves shown on these plots are spline fits to the individual data points. Values of all independent test variables are displayed in the key above each plot. Pitching moment values for this data set are presented at an estimated, realistic vehicle center of gravity location, shown in the key for the 3.03\%-scale model. Thus precise determination of full-scale vehicle pitch stability levels and trim angles should not be made from these curves.

Effect of Mach Number: Figure 17 shows the effect of Mach number variation on longitudinal aerodynamic coefficients in both the body and stability axes. All data shown are at a diameter-based Reynolds number of 1.5 million with LaRC distributed grit applied to the model as described in Section IV. Data plots in subsequent sections will show that for the range of Reynolds numbers tested and for the trip configurations that were run, Mach number variations are not dependent on these parameters. Data show the CEV configuration to be statically stable for this center of gravity location, with stability increasing with increasing Mach number. The trim angle increases from approximately $144^{\circ}$ at the lowest Mach numbers $(\mathrm{M} \leq 2.0)$ to approximately $149^{\circ}$ at $\mathrm{M}=4.0$. The greatest variation in pitching moment with Mach number is seen at the lowest angle of attack tested $\left(\square \approx 140^{\circ}\right)$. Data at the highest angle of attack show pitching moment values to be constant over the Mach range tested. Normal force coefficient values are small, decreasing with increasing angle of attack, but nearly constant over the range of Mach numbers. Axial force values are much larger than normal force values and decrease systematically with Mach number, with much less variation at the higher angles of attack. These same axial force trends are seen in both the lift and drag data and thus their ratio, $\mathrm{L} / \mathrm{D}$, is effectively invariant with Mach number. $\mathrm{L} / \mathrm{D}$ values in the trim region for this range of Mach numbers vary from approximately 0.55 to 0.45 .

Effect of Reynolds Number: Figure 18 shows the effect of Reynolds number variation on longitudinal aerodynamic coefficients in both the body and stability axes for the CEV configuration with LaRC transition grit applied at $M=1.6$. Very small effects of Reynolds number are seen on axial force coefficient over the entire angle of attack range. With slight decreases in axial force with increasing Reynolds number for $\square<166^{\circ}$, Figure 18 shows resultant decreases in drag over the same angle of attack range. No significant Reynolds number effects are seen on lift coefficient or lift-to-drag ratio. Very small variations are observed in pitching moment over narrower angle of attack ranges, but there is no effect at the trim angle of attack. Not shown are Reynolds number variations for 
aerodynamic data at $\mathrm{M}=2.5$ as well for the model without grit which show similarly small Reynolds number effects for all longitudinal coefficients.
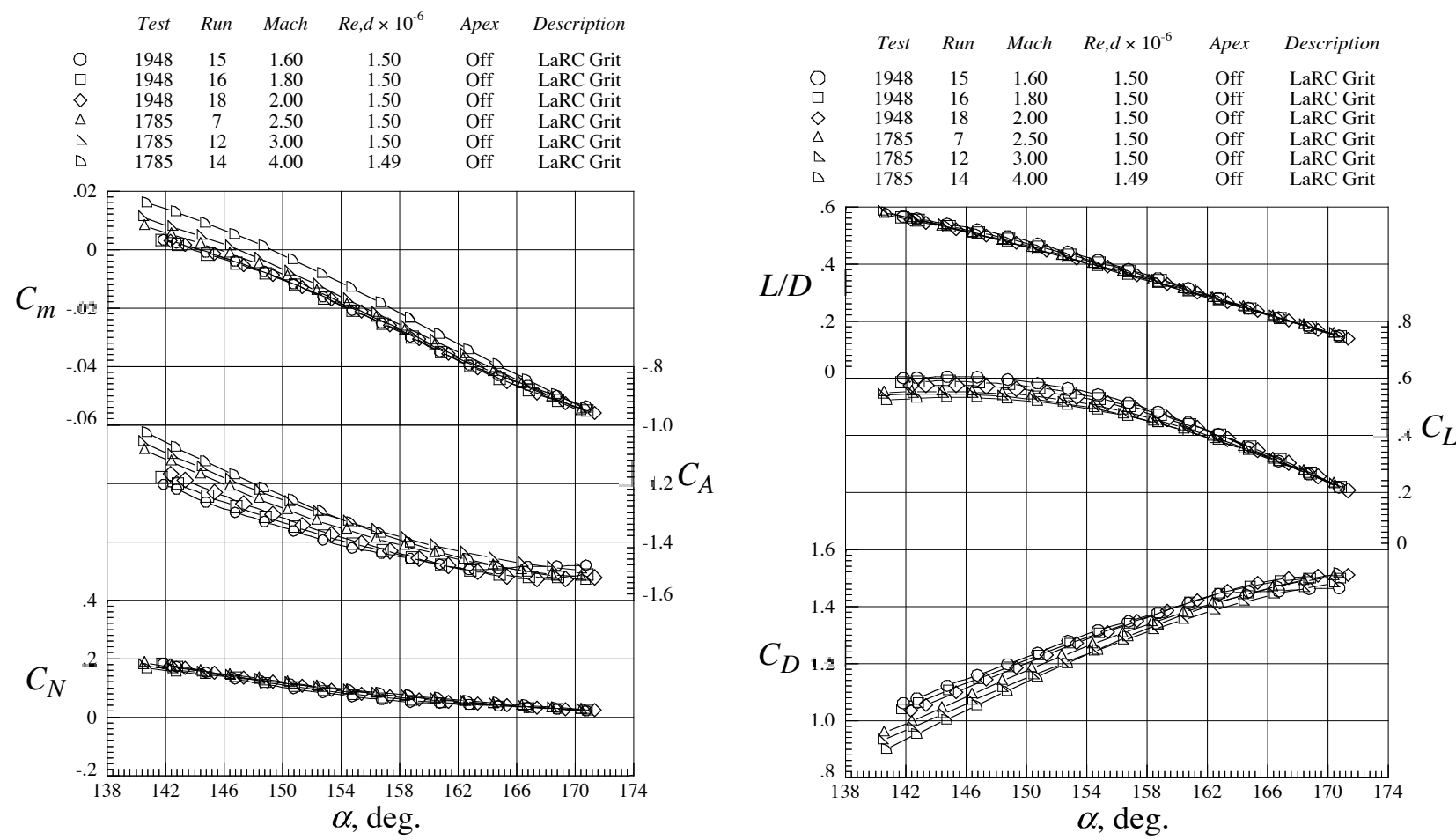

Figure 17. Effect of Mach number on body-axis and stability-axis longitudinal aerodynamic coefficient data with $L a R C$ grit for $\operatorname{Re}_{d}=1.5 \times 10^{6}$.
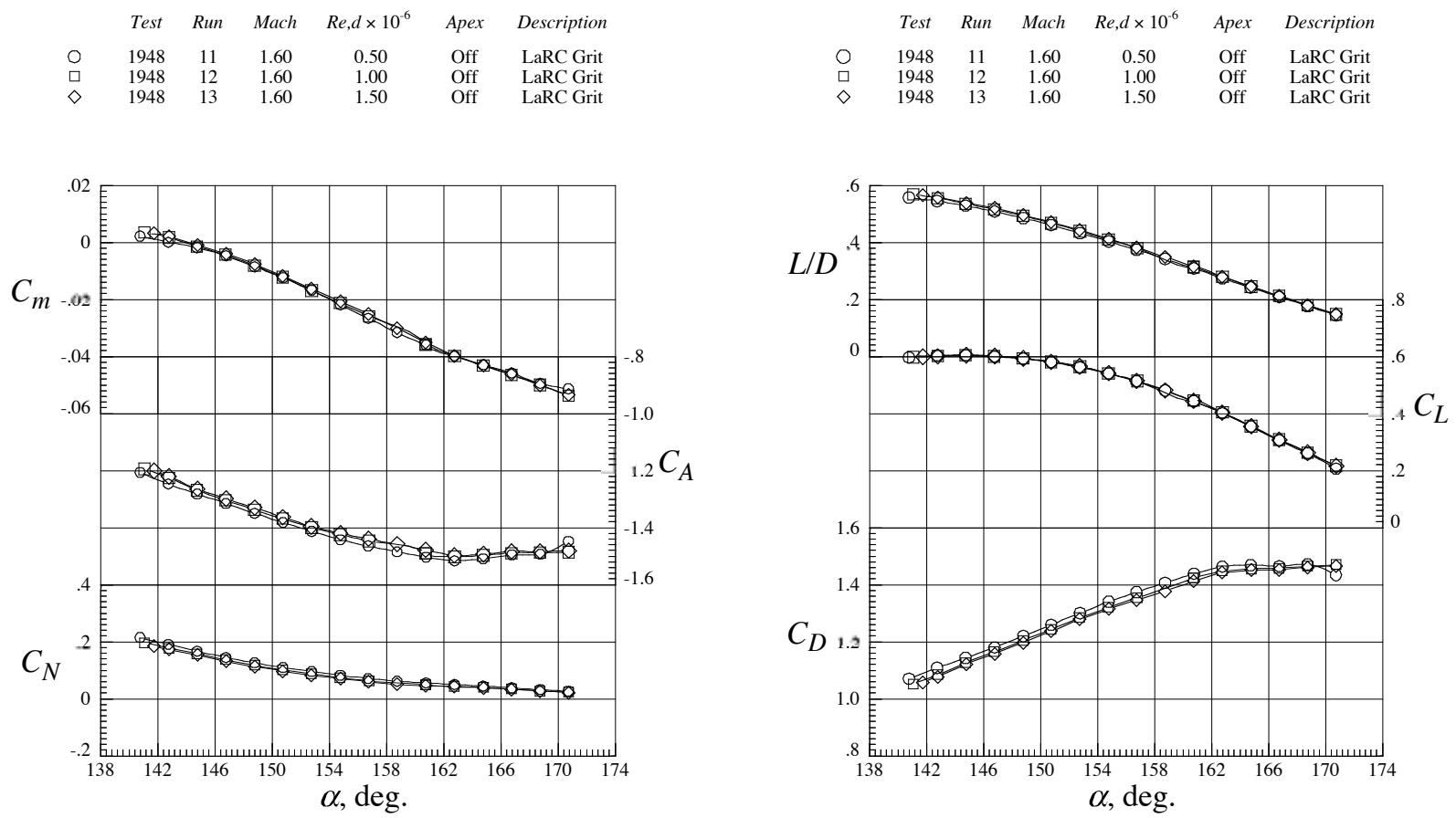

Figure 18. Effect of Reynolds number on body-axis and stability-axis longitudinal aerodynamic coefficient data with LaRC grit for the CEV configuration in the LaRC UPWT at M=1.6. 
Effect of Apex Cover: Figure 19 shows the effect of the apex cover on body-axes longitudinal aerodynamic coefficients for $\mathrm{M}=1.6, \mathrm{M}=2.5$, and $\mathrm{M}=4.0$. Data on all plots were measured at $\mathrm{Re}_{\mathrm{d}}=1.5 \times 10^{6}$ for the LaRC Grit configuration. Normal and Axial force coefficients show no significant changes with apex configuration for any Mach number tested. Pitching moment coefficient shows an increasing increment due to the apex cover with decreasing angle of attack and decreasing Mach number. At $M=1.6, \square=141^{\circ}$, pitching moment coefficient increases by approximately 0.006 with the apex cover. In contrast, no differences are observed at the highest Mach number $(\mathrm{M}=4.0)$ and highest angles of attack $\left(\square>162^{\circ}\right)$ where the apex is likely within the wake region.
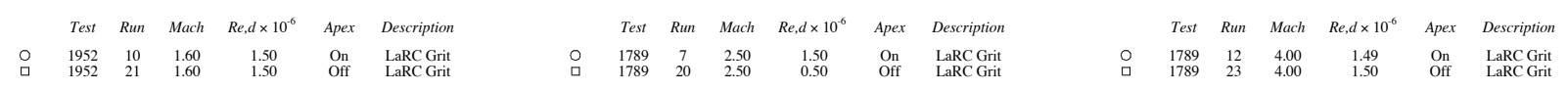

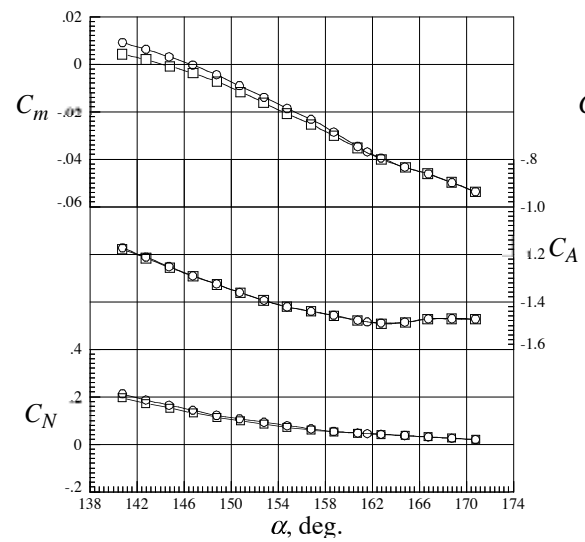

(a) $M=1.6$

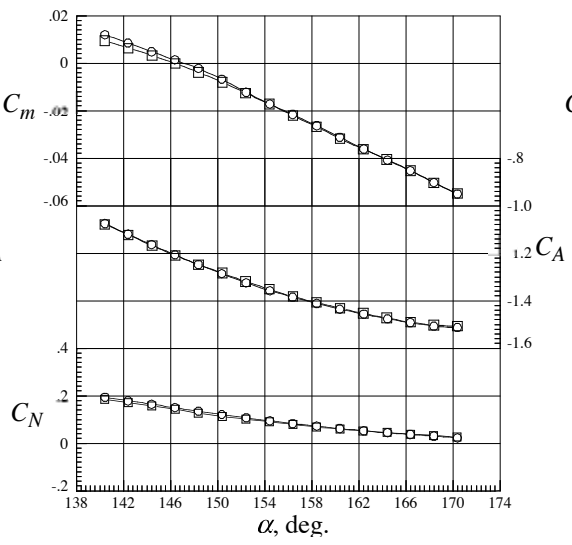

(b) $\mathrm{M}=\mathbf{2 . 5}$

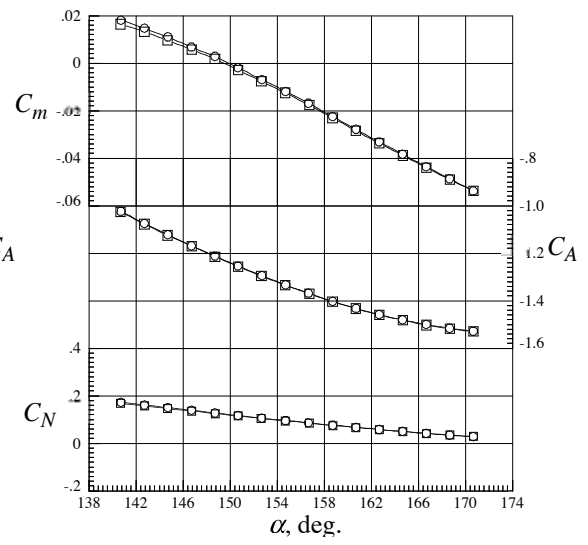

(c) $M=4.0$

Figure 19. Effect of apex cover on body-axis longitudinal aerodynamic coefficient data with LaRC grit for the CEV configuration in the LaRC UPWT at $\operatorname{Re}_{d}=1.5 \times 10^{6}$ for $M=1.6, M=2.5$, and $M=4.0$.

Effect of Trips: Figure 20 shows a representative comparison of the effects of LaRC transition grit versus ARC trip dots (as explained in Section IV) on longitudinal aerodynamic coefficients in the body axes for $\operatorname{Re}_{\mathrm{d}}=1.5 \times 10^{6}$ and $M=1.6$. No measurable differences in longitudinal data were observed for any Mach numbers or Reynolds numbers when comparing the CEV with LaRC transition grit and with ARC trip dots applied, thus only LaRC trip grit data will be used in comparisons below.
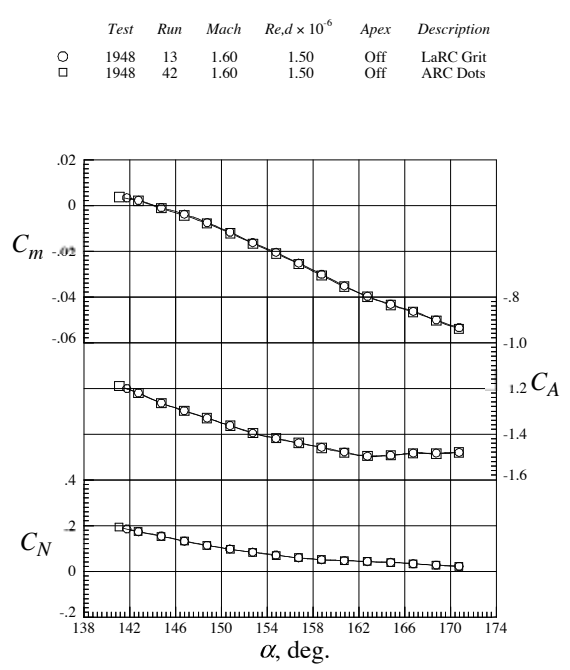

Figure 20. Comparison of LaRC grit and ARC trip dots for the CEV configuration in LaRC UPWT at $\operatorname{Re}_{\mathrm{d}}=1.5 \times 10^{6}, \mathrm{M}=1.6$.
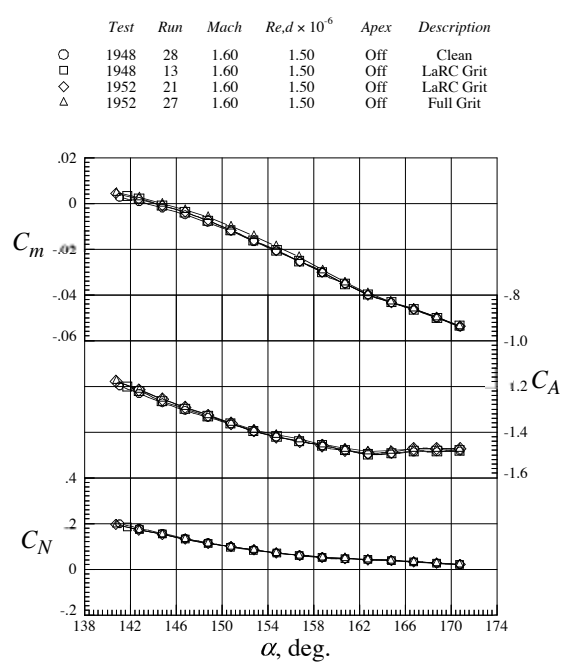

(a) $M=1.6$

Figure 21. Effect of trips for the CEV configuration in LaRC UPWT at $R_{d}=1.5 \times 10^{6}$ for $M=1.6$ and $M=2.5$.
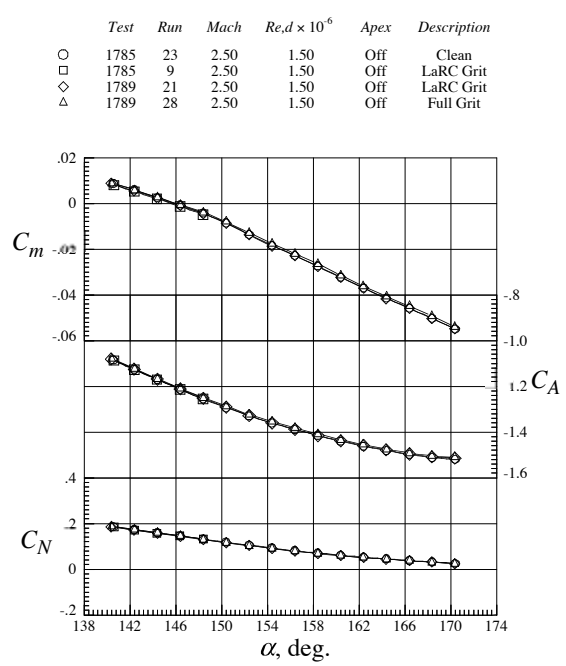

(b) $\mathrm{M}=2.5$ 
Comparisons are plotted for a configuration without grit, with the LaRC grit ring, and with full grit (as described in Section IV) at $\mathrm{Re}=1.5 \times 10^{6}$ for $\mathrm{M}=1.6$ and $\mathrm{M}=2.5$. Very small effects are seen on axial force, drag, and pitching moment at various angles. The trim angle of attack, shown in Figure 21(a) varies over approximately a $1^{\circ}$ range for various grit configurations for $M=1$.6. Figure 21(b) shows no differences for any of the longitudinal data at $M=2.5$ or above (not shown) for the CEV with and without transition grit. Given the companion set of IR and TSP results in the preceding section, one can conclude that forebody transition effects on aerodynamics are small at these test conditions and decrease with increasing Mach number.

Reproducibility: Figure 22(a) shows within-test reproducibility of body-axis longitudinal aerodynamic coefficients for the CEV configuration at $\mathrm{M}=2.5$. In order to generate statistically-based uncertainty analyses, sets of repeat runs were done at the beginning, the middle, and then end of the test entry. These data sets were collected at a condition of $\operatorname{Re}_{\mathrm{d}}=1.5 \times 10^{6}$ with LaRC grit applied to the model at $\mathrm{M}=1.6$ and $\mathrm{M}=2.5$. Note that through the course of the test entry, transition grit was applied, removed, and then applied again, so these runs show the withintest reproducibility relative to flow conditions, instrumentation, and model surface configuration. Although it cannot be observed from Figure 22(a) due to the scale required to display the full range of data, reproducibility

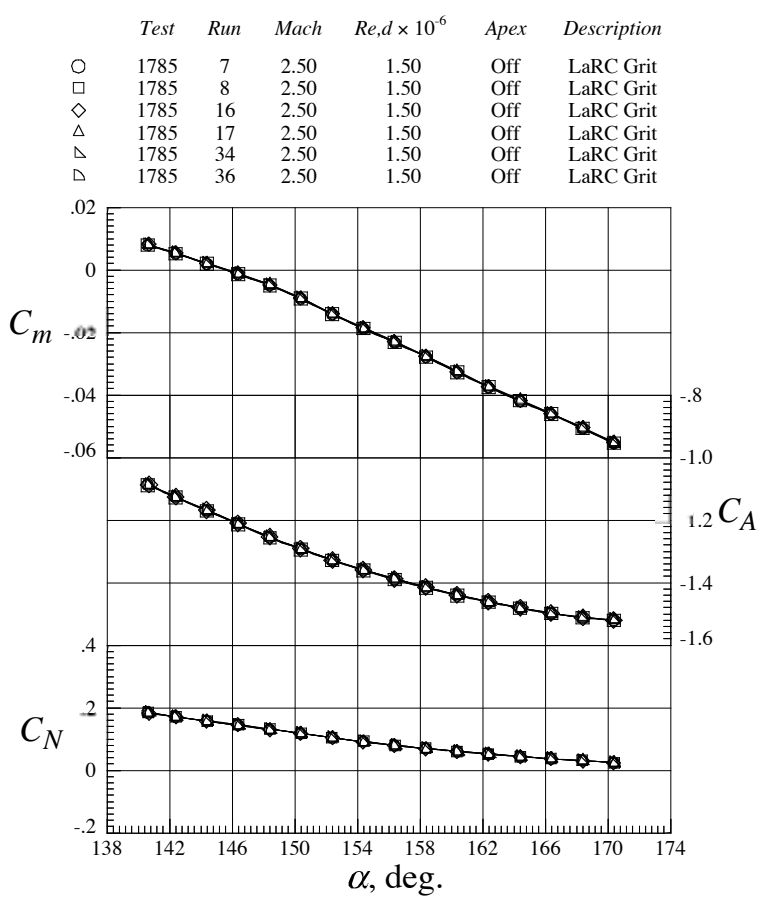

(a) Within-test reproducibility
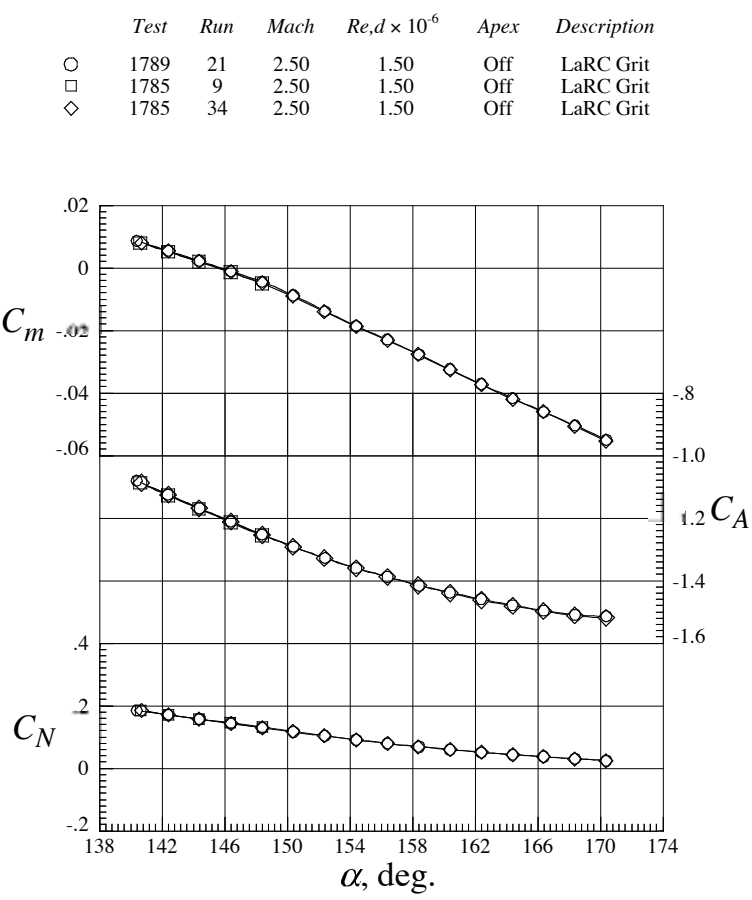

(b) Test-to-test reproducibility

Figure 22. Within-test and test-to-test reproducibility on body-axis longitudinal aerodynamic coefficient data with LaRC grit for the CEV configuration at $\operatorname{Re}_{\mathrm{d}}=1.5 \times 10^{6}, \mathrm{M}=2.5$.

within the test was generally on the order of the balance accuracies shown in Table 3, lending confidence to facility and instrumentation stability. Figure 22(b) is a comparable plot at $\mathrm{M}=2.5$ showing test-to-test (UPWT Tests 1785 and 1789) reproducibility for longitudinal aerodynamic coefficients. Test-to-test reproducibility was also observed to be on the order of the balance accuracies, giving high confidence to consistency in model installation and facility and instrumentation operation. These data provide the basis for additional uncertainty analyses to be done in conjunction with comparable data obtained in the Ames Unitary Plan Facility to mature uncertainty estimates to include model-to-model and facility-to-facility effects.

Data Uncertainty: The CEV program has adopted a standard uncertainty analysis for all wind tunnel test data sets based on the principles of statistical quality control. ${ }^{12}$ Papers by Hemsch, et al. ${ }^{13}$ detail implementation of these techniques in Langley wind tunnel facilities. A report showing standard uncertainty calculations for all experimental aerodynamic data obtained in support of the CEV program will be part of the official CEV program documentation. A complete explanation and presentation of uncertainty calculations for testing in the LaRC UPWT is beyond the scope of this paper, but a sample plot of test-to-test range data and a summary of calculated uncertainty estimates for longitudinal aerodynamic coefficients is presented herein. 


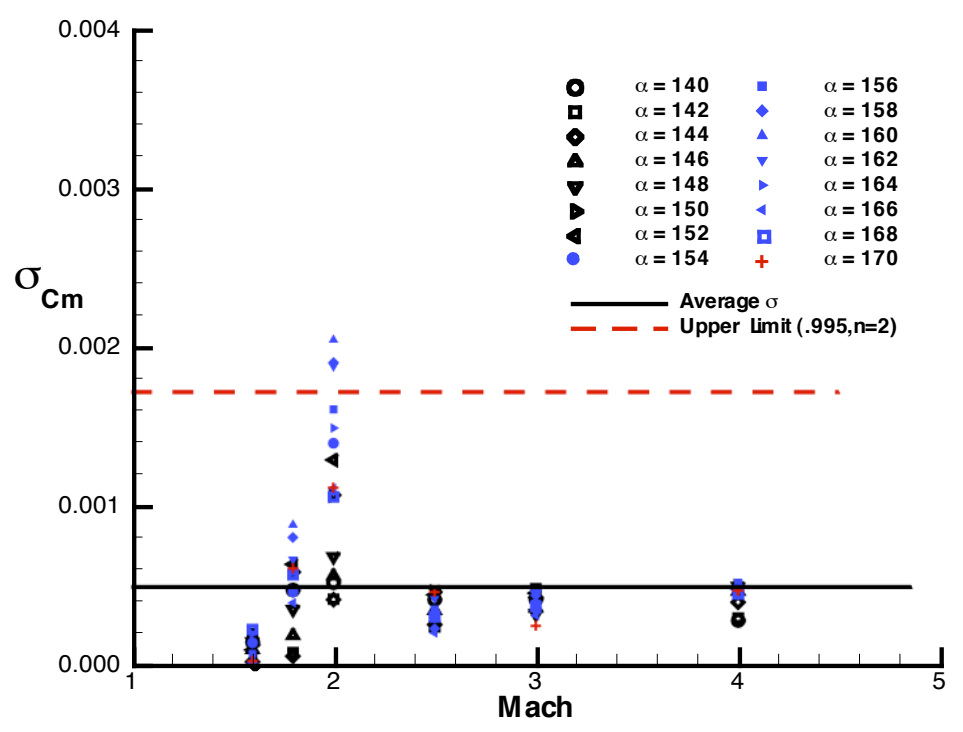

Figure 23. Variation in estimated standard deviation of pitching moment as a function of Mach number for the $3.03 \%$-scale CEV model in the LaRC UPWT.

Figure 23 shows estimates of standard deviation computed for the pitching moment coefficient using calculated across-test ranges (maximum minus minimum data values) for each angle of attack as a function of Mach number. All angles were interpolated to nominal values (every 2 deg.). The average standard deviation is the average of all angles and Mach numbers for comparison to determine if the dispersion information can be pooled and a single number used. The upper limit is calculated based on the range distribution for a sample of size 2 where 0.995 is the probability of the data lying below the limit. Figure 23 clearly shows a greater variation in the data in Test Section I $(\mathrm{M} \leq 2.0)$, with the largest variation at $\mathrm{M}=2$. No explanation is readily given without further analysis to examine facility and/or configuration-specific causes.

Plots similar to Figure 23 were used to generate uncertainty estimates for all

longitudinal aerodynamic data for CEV testing in LaRC UPWT. Table 7 shows a tabular summary for body-axis and stability-axis $\pm 2 \square$ uncertainty values as a function of Mach number. For the calculation of the standard deviations given in the table, an average standard deviation across the angles of attack was used for each Mach number.

Table 7. Uncertainty $( \pm 2 \square)$ estimates for longitudinal aerodynamic data from LaRC UPWT.

\begin{tabular}{|l|r|r|r|r|r|r|}
\hline $\mathbf{M}$ & \multicolumn{1}{|l|}{ CN } & \multicolumn{1}{|l|}{ CA } & Cm & CL & CD & \multicolumn{1}{l|}{ L/D } \\
\hline 1.6 & 0.0019 & 0.00798 & 0.0004 & 0.00278 & 0.00738 & 0.00154 \\
\hline 1.8 & 0.00162 & 0.00788 & 0.001 & 0.00298 & 0.0076 & 0.00144 \\
\hline 2.0 & 0.00404 & 0.01346 & 0.00232 & 0.00874 & 0.01106 & 0.00404 \\
\hline 2.5 & 0.00114 & 0.00412 & 0.00074 & 0.0009 & 0.0042 & 0.0009 \\
\hline 3.0 & 0.0017 & 0.00184 & 0.00082 & 0.0019 & 0.00174 & 0.00162 \\
\hline 4.0 & 0.0027 & 0.00186 & 0.00094 & 0.00288 & 0.00174 & 0.00244 \\
\hline
\end{tabular}

\section{$\underline{\text { Static Pressure Studies }}$}

Figures 24 through 30 present static surface pressure data from LaRC UPWT Tests 1954 and 1791 obtained with a 6-inch diameter CEV model. These test entries produced data from 81 discrete taps at 16 angles of attack for 3 Reynolds numbers and 2 surface configurations. Given this large body of data, only a small subset relevant to particular effects will be presented in this report. Pressure data is presented in the form of a nondimensional pressure coefficient plotted versus non-dimensional X coordinate in the model reference axes. Symbols represent pressure measurements at individual pressure orifices. Curves shown on these plots are spline fits to the individual data points. Values of all independent test variables are displayed in the key above each plot. The pressure data selected for these plots is the centerline array on the heat shield and both sides of the conical aftbody to examine both windward and wake pressure levels. Figure 24 shows a plot of a single centerline surface pressure distribution for the CEV model at $\mathrm{M}=1.6, \square \approx 140^{\circ}$, and $\mathrm{Re}_{\mathrm{d}}=1.5 \times 10^{6}$. The spline-fit curve can be thought to start at the center tap (\#100) and connect pressure tap data corresponding to taps in the negative $\mathrm{Z}$ directions (\#302-\#338) and connecting to taps in the positive $\mathrm{Z}$ direction on the conical aftbody through which the sting exits and back around to the windward heat shield (\#236-\#202). The reader is referred back to Figure 6 to see these arrays on the model schematic. Data in subsequent figures are primarily presented at nominal angles of attack of $140^{\circ}, 156^{\circ}$, and $170^{\circ}$ to highlight pressure variations over the entire angle-of-attack range. 
Test Run Point Mach Re,d $\square 10^{-6} \quad$ Apex Description $\alpha$, deg.

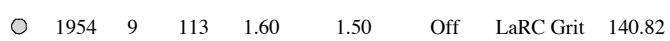

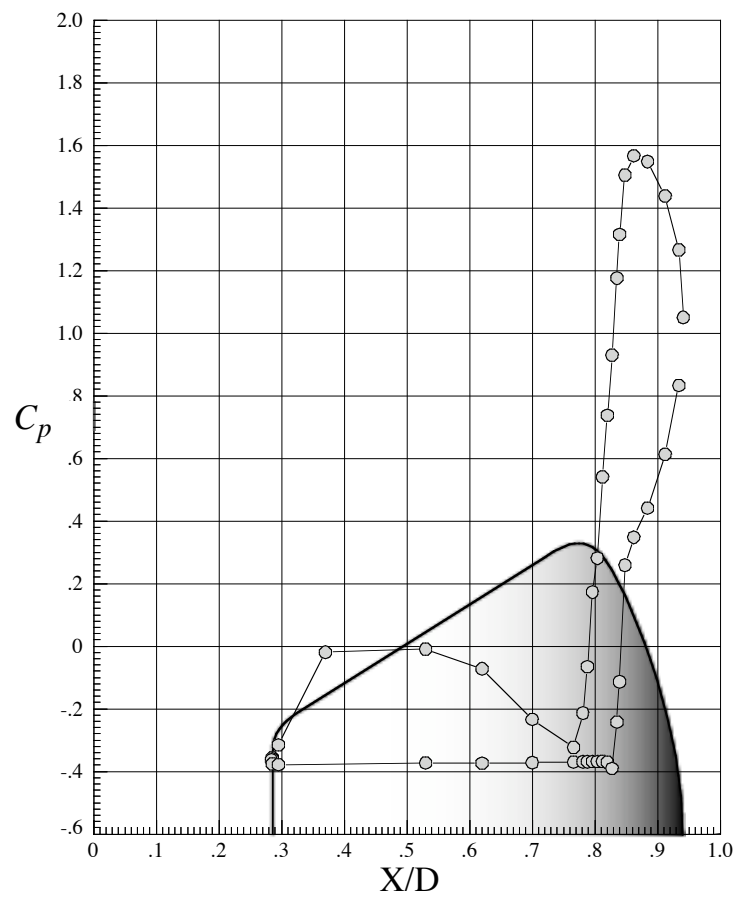

Figure 24. Typical centerline surface static pressure distribution for $\mathrm{CEV}$ model in LaRC UPWT.
Effect of Angle of Attack: Figure 25 shows the effect of angle of attack on centerline surface pressure coefficient data for Mach numbers 1.6, 1.8, 2.0, 2.5, 3.0 and 4.0. The complexity of these plots highlight the fact that pressure levels are more sensitive to angle of attack than any of the other flow (Mach number, Reynolds number) or configuration (surface roughness) parametric variables examined in this test program. (The effects of these variables will be described in sections to follow.) The maximum pressure coefficient observed on the windward face is relatively constant for a given Mach number, but this maximum is observed at a slightly smaller value of $\mathrm{X} / \mathrm{D}$ with increasing angle of attack as the stagnation point moves away from the center of the heat shield with decreasing angle of attack. A dramatic decrease in pressure coefficient is seen for all angles of attack and all Mach numbers with decreasing $\mathrm{X} / \mathrm{D}$ in the shoulder region where the body transitions from the blunt heat shield to the conical aftbody. Aftbody pressure levels show the most variation with angle of attack. The highest angle of attack, nominally $\square \approx 170^{\circ}$, shows near symmetry in the pressures on the $+Z$ (sting exit side) and $-Z$ side of the aftbody $(X / D<0.8)$, with essential constant pressure coefficient values closely approximated by $\mathrm{C}_{\mathrm{P}}=-1 / \mathrm{M}^{2}$. The distributions at $\square \approx 156^{\circ}$ show slight increases in $C_{P}$ for the $-Z$ side of the aftbody as it is now more closely aligned with the angle of the freestream flow. As the angle of attack is decreased to its minimum value for these tests, $\square \approx 140^{\circ}$, the $-Z$ side of the aftbody is now a windward surface for all Mach numbers and the surface pressures recover to much higher values after the separation and reattachment downstream of the shoulder region.

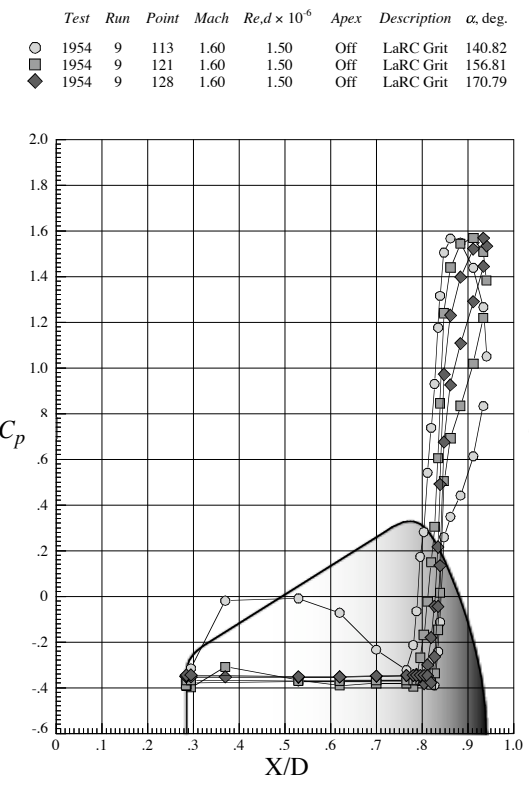

(a) $M=1.6$

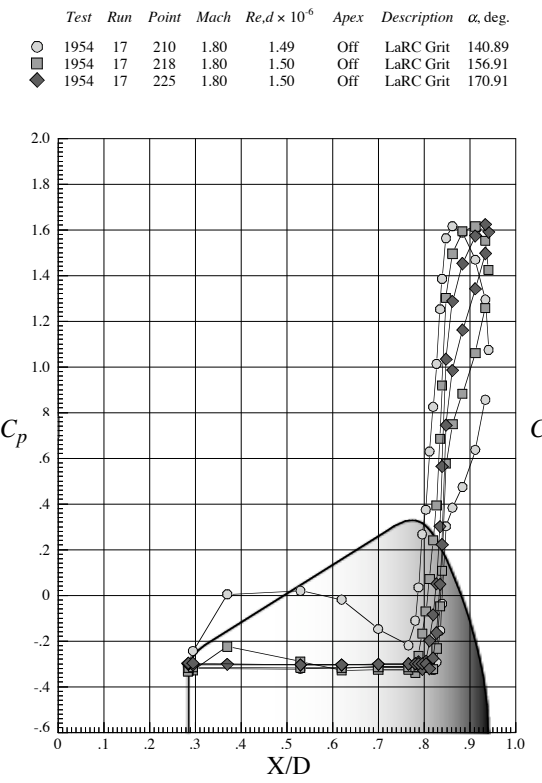

(b) $\mathrm{M}=1.8$
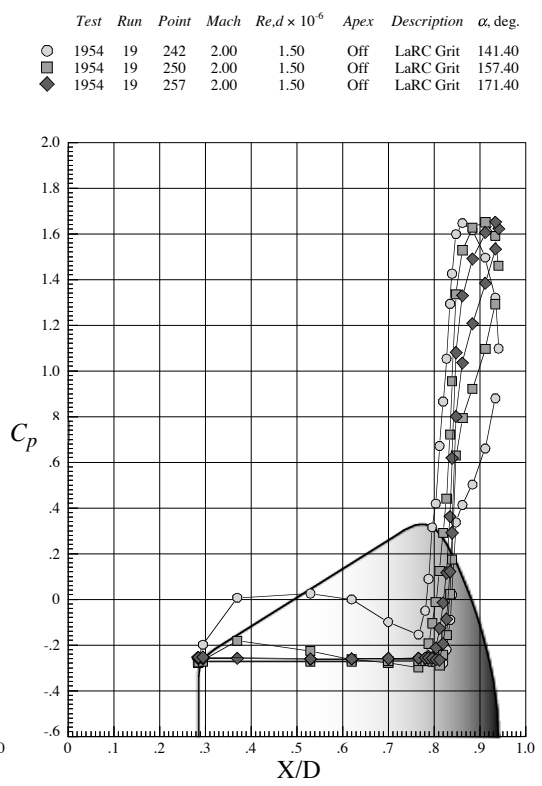

(c) $\mathrm{M}=\mathbf{2 . 0}$

Figure 25. Effect of angle-of-attack on centerline surface static pressure data for CEV model with LaRC grit pattern for $\operatorname{Re}_{d}=1.5 \times 10^{6}$ at $M=1.6, M=1.8, M=2.0, M=2.5, M=3.0$, and $M=4.0$. 


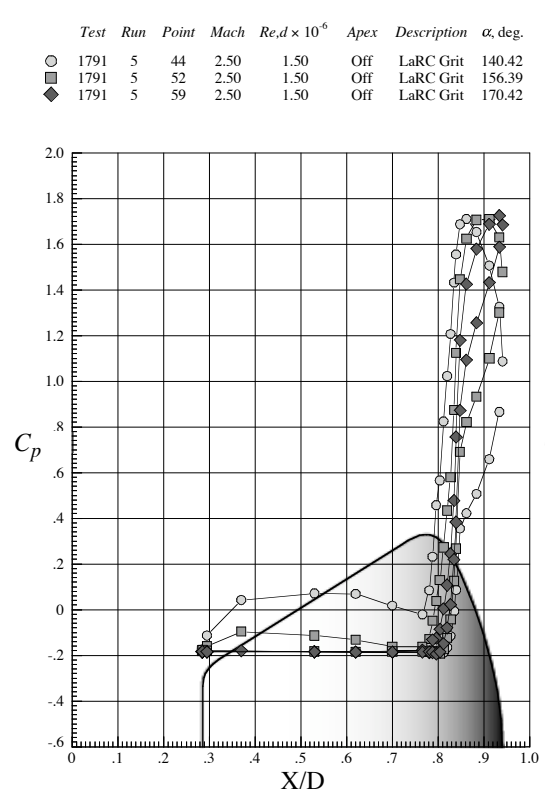

(d) $M=2.5$
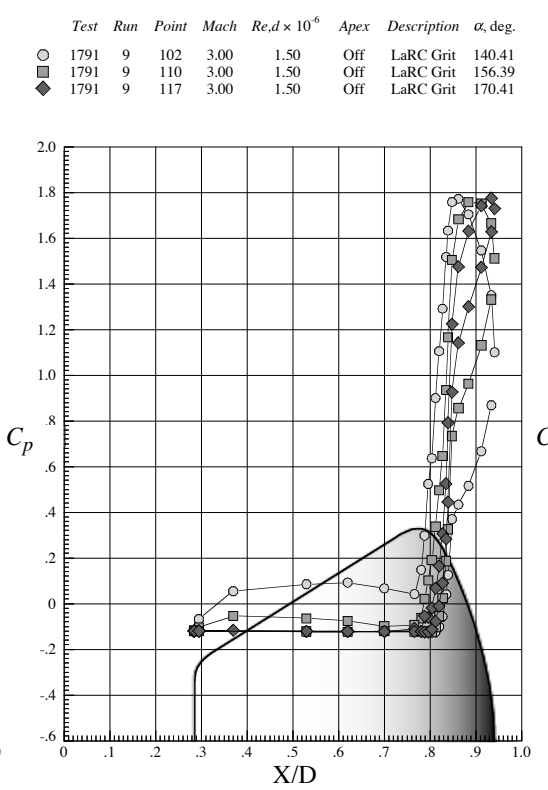

(e) $\mathrm{M}=3.0$
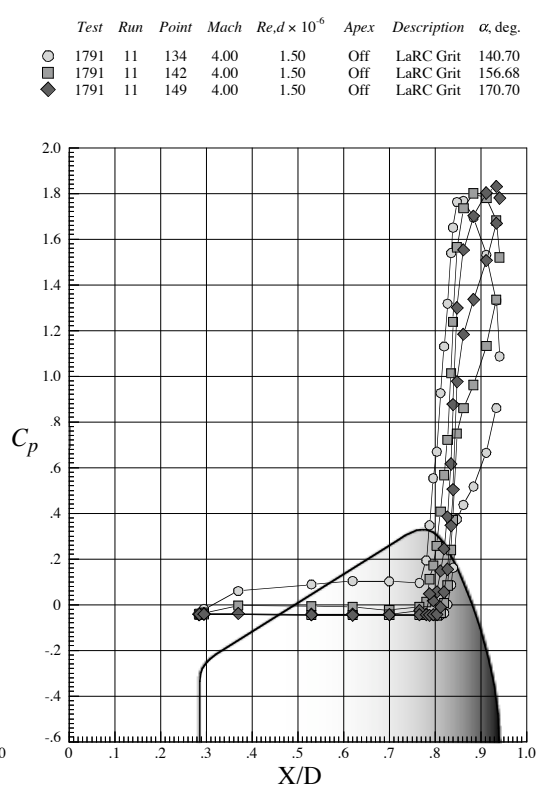

(f) $M=4.0$

Figure 25 (cont.). Effect of angle-of-attack on centerline surface static pressure data for CEV model with LaRC grit pattern for $R_{d}=1.5 \times 10^{6}$ at $M=1.6, M=1.8, M=2.0, M=2.5, M=3.0$, and $M=4.0$.

Effect of Mach Number: Figure 26 shows the effect of Mach number variation on centerline surface pressure coefficient data for $\square \approx 140^{\circ}, \square \approx 156^{\circ}$, and $\square \approx 170^{\circ}$. All data shown are at a diameter-based Reynolds number of 1.5 million per foot and with LaRC distributed grit applied to the model. Figures 26 (a) and 26(d) show pressure coefficient data for Mach numbers in LaRC UPWT Test Section $1(\mathrm{M}=1.6,1.8$, and 2.0) and Test Section 2 $\left(\mathrm{M}=2.5,3.0\right.$, and 4.0) respectively for $\square \approx 140^{\circ}$. Maximum $\mathrm{C}_{\mathrm{P}}$ values range from 1.57 at $\mathrm{M}=1.6$ to 1.78 at $\mathrm{M}=4.0$ are observed to be very close to the heat shield shoulder where pressure fall off rapidly as the flow encounters the rapid change in surface curvature. Pressures on the heat shield centerline converge to constant values for the two highest Mach numbers. Pressures in the $+Z$ shoulder region drop below freestream values for all Mach Numbers, with minimum pressure coefficients ranging from -0.4 at $M=1.6$ to -0.04 at $M=4.0$. Surface pressures remain nearly constant at these values along the $+Z$ side of the aft body on both sides of the support sting exiting the model in the vicinity of $X / D=0.4$. Pressures in the $-Z$ shoulder region near the stagnation point drop below free stream value for $M=1.6$ to $M=2.5$ with minimum $C_{P}$ values ranging from -0.32 to -0.02 . Minimum $C_{P}$ values for $M=3.0$ and $M=4.0$ are 0.05 and 0.10 , respectively. As mentioned in the preceding section, pressures on the $-Z$ aftbody for $\square \approx 140^{\circ}$ recover to near or above freestream values as the aftbody angle is positive relative to the freestream flow. Figures 26(b), 26(c), 26(e), and 26(f) show the effects of Mach number on centerline static pressures for $\square \approx 156^{\circ}$ and $\square \approx 170^{\circ}$. Many of the same characteristics described for the $\square \approx 140^{\circ}$ curves can be seen for the higher angles with aftbody pressure coefficient values symmetric in $-Z$ and $+Z$ at $\square \approx 170^{\circ}$.

In examining Mach number effects shown in Figure 26, one observes that there are run-to-run differences in angle of attack as much as $0.4^{\circ}$. With no force balance and corresponding real-time load measurement, sting corrections had be done post-test using loads measured in previous force testing and then applied to the pressure model and sting. Thus it was difficult to precisely match angles of attack for different Mach numbers. Given the sensitivity to angle of attack shown previously, one might question whether variations believed to be due to Mach number were also a function of angle of attack variation. Thus runs were done in fine (approximately $0.1^{\circ}$ ) increments around a nominal angle of attack to assess angle-of-attack sensitivity. Figure 27 shows changes in measured pressure coefficients at $\mathrm{M}=1.6$ and $\mathrm{M}=2.5$ over a range of angles of attack centered around $\square \approx 154^{\circ}$ to be negligible compared with observed Mach number effects discussed in the preceding paragraph. 
Test Run Point Mach Re,d $\square 10^{-6} \quad$ Apex Description $\alpha$, deg. $\begin{array}{lllllllll}\circ & 1954 & 9 & 113 & 1.60 & 1.50 & \text { Off } & \text { LaRC Grit } & 140.82 \\ 0 & 1954 & 17 & 210 & 1.80 & 1.49 & \text { Off } & \text { LaRC Grit } & 140.89\end{array}$

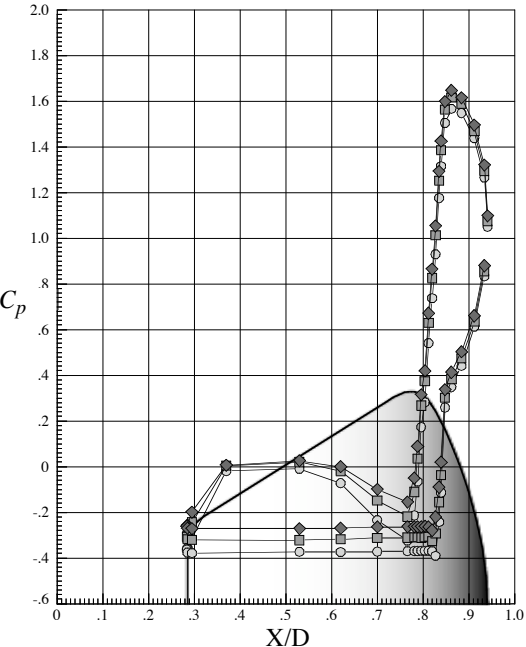

(a) $\square \approx 140^{\circ}$

Test Run Point Mach Re,d $\square 10^{-6}$ Apex Description $\alpha$, deg. $\begin{array}{lllllllll}\circ & 1791 & 5 & 44 & 2.50 & 1.50 & \text { Off } & \text { LaRC Grit } & 140.42 \\ 0 & 1791 & 9 & 102 & 3.00 & 1.50 & \text { Off } & \text { LaRC Grit } & 140.41\end{array}$ $\begin{array}{lllllllll} & 1791 & 11 & 134 & 4.00 & 1.50 & \text { Off } & \text { LaRC Grit } & 140.70\end{array}$

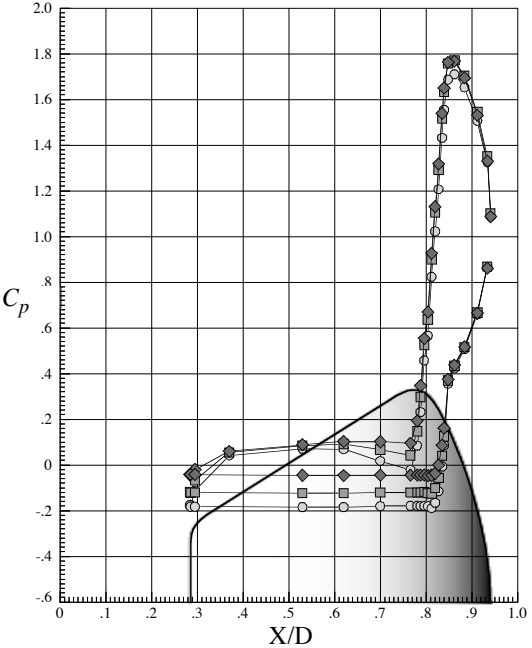

(d) $\square \approx 140^{\circ}$
Test Run Point Mach Re,d $\square 10^{-6}$ Apex Description $\alpha$, deg. $\begin{array}{lllllllll}0 & 1954 & 9 & 121 & 1.60 & 1.50 & \text { Off } & \text { LaRC Grit } & 156.81 \\ 1954 & 17 & 218 & 1.80 & 1.50 & \text { Off } & \text { LaRC Grit } & 156.91\end{array}$

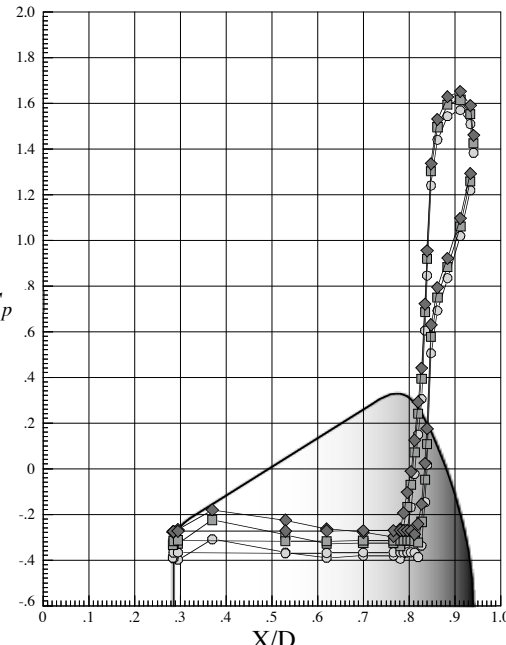

(b) $\square \approx 156^{\circ}$

Test Run Point Mach Re,d $\square 10^{-6}$ Apex Description $\alpha$, deg. $\begin{array}{lllllllll}\circ & 1791 & 5 & 52 & 2.50 & 1.50 & \text { Off } & \text { LaRC Grit } & 156.39\end{array}$ \begin{tabular}{lllllllll}
\hline & 1791 & 9 & 110 & 3.00 & 1.50 & Off & LaRC Grit & 156.39 \\
& 1791 & 11 & 142 & 4.00 & 1.50 & Off & LaRC Grit & 156.68
\end{tabular}

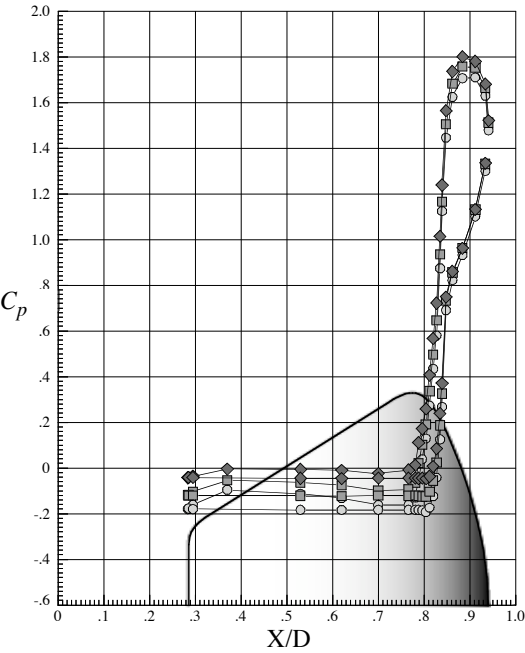

(e) $\square \approx 156^{\circ}$
Test Run Point Mach Re,d $\square 10^{-6}$ Apex Description $\alpha$, deg. $\begin{array}{lllllllll}0 & 1954 & 9 & 128 & 1.60 & 1.50 & \text { Off } & \text { LaRC Grit } & 170.79 \\ 0 & 1954 & 17 & 225 & 1.80 & 1.50 & \text { Off } & \text { LaRC Grit } & 170.91 \\ \diamond & 1954 & 19 & 257 & 2.00 & 1.50 & \text { Off } & \text { LaRC Grit } & 171.40\end{array}$

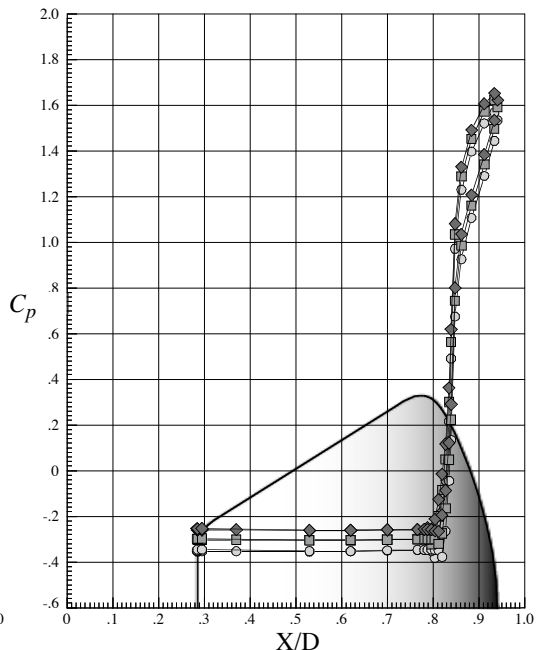

(c) $\square \approx 170^{\circ}$

Test Run Point Mach Re, $d \square 10^{-6}$ Apex Description $\alpha, \mathrm{deg}$ \begin{tabular}{lllllllll}
$\circ$ & 1791 & 5 & 59 & 2.50 & 1.50 & Off & LaRC Grit & 170.42 \\
口 & 1791 & 9 & 117 & 3.00 & 1.50 & Off & LaRC Grit & 170.41 \\
\hline & 1791 & 11 & 149 & 4.00 & 1.50 & Off & LRC Grit & 170.70
\end{tabular}

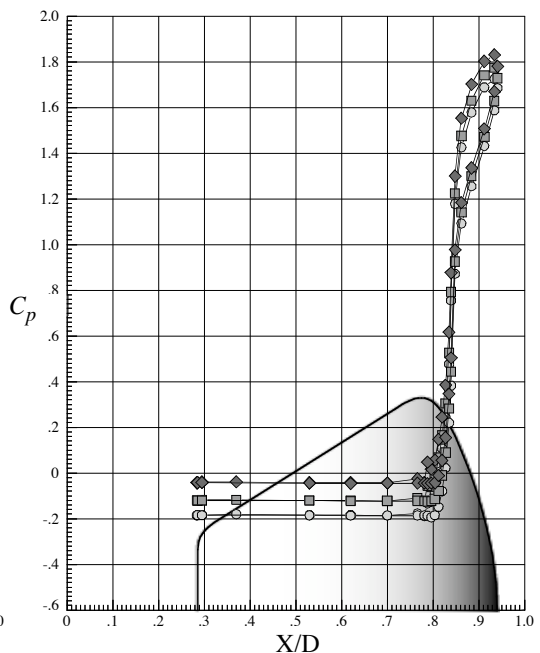

(f) $\square \approx 170^{\circ}$

Figure 26. Effect of Mach number on centerline surface static pressure data for CEV model with LaRC grit pattern in the $L a R C U P W T$ for $\operatorname{Re}_{d}=1.5 \times 10^{6}$ at $\square \approx 140^{\circ}, \square \approx 156^{\circ}$, and $\square \approx 170^{\circ}$. 

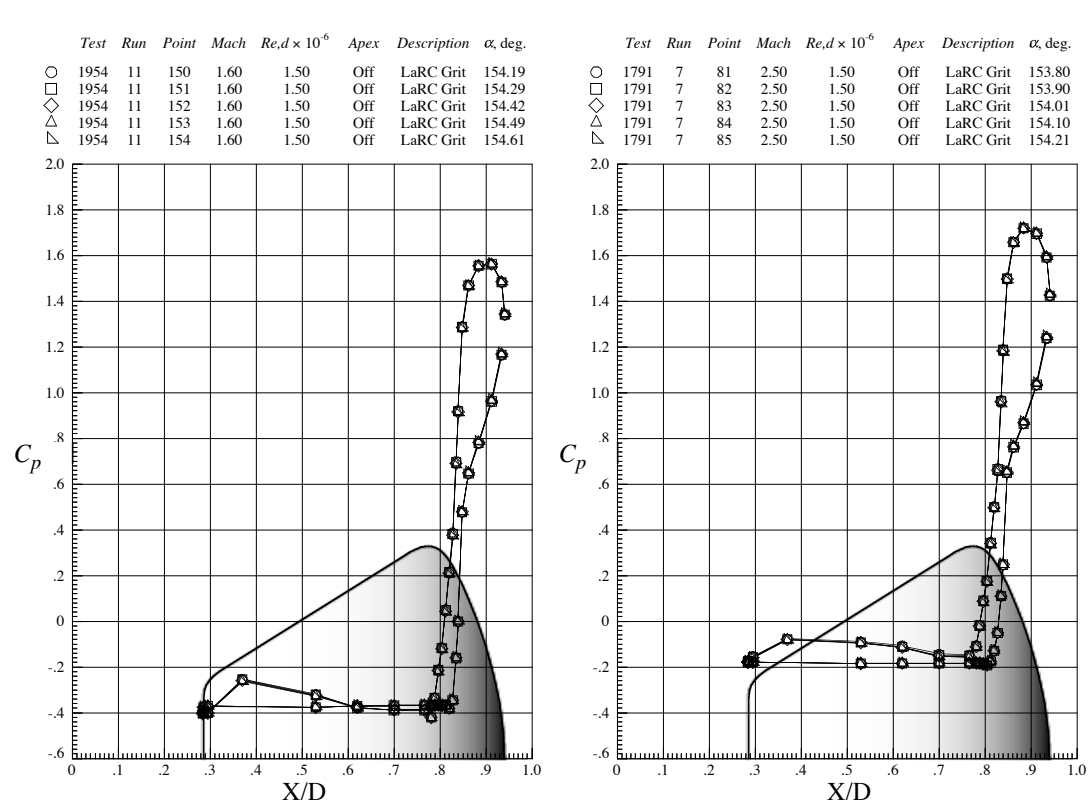

Figure 27. Angle-of-attack sensitivity of centerline surface static pressure data with LaRC grit in the LaRC UPWT at $\square \approx 154^{\circ}$, $\operatorname{Re}_{\mathrm{d}}=1.5 \times 10^{6}$ for $M=1.6$ and $M=2.5$.
Effect of Reynolds Number: Figure 28 shows the effect of Reynolds number variation on centerline static surface pressure distributions for a gritted configuration at $\mathrm{M}=2.5$ for three angles of attack. In general Reynolds number effects are small and confined to the "leeward" aftbody. These observed differences generally appear to be greatest at the lowest angles of attack and at the lowest Reynolds number, although the data support no correlated trends. Data at all other Mach numbers and grit configurations showed similarly small effects of Reynolds number. No significant changes in longitudinal aerodynamic coefficients were observed with Reynolds number in previous force and moment testing, and thus this set of pressure data support these conclusions.

Effect of Trips: Figure 29 shows the effect of transition grit on centerline static surface pressure distributions for $\square \approx 140^{\circ}, \square \approx 156^{\circ}$, and $\square \approx 170^{\circ}$ at $\mathrm{M}=1.6$ at $\mathrm{Re}_{\mathrm{d}}=1.5 \times 10^{6}$. No significant differences are observed for any angle of attack with and without transition grit. Although not presented in this report, data at other Mach numbers and Reynolds numbers all show no systematic effect of grit on measured surface static pressures.
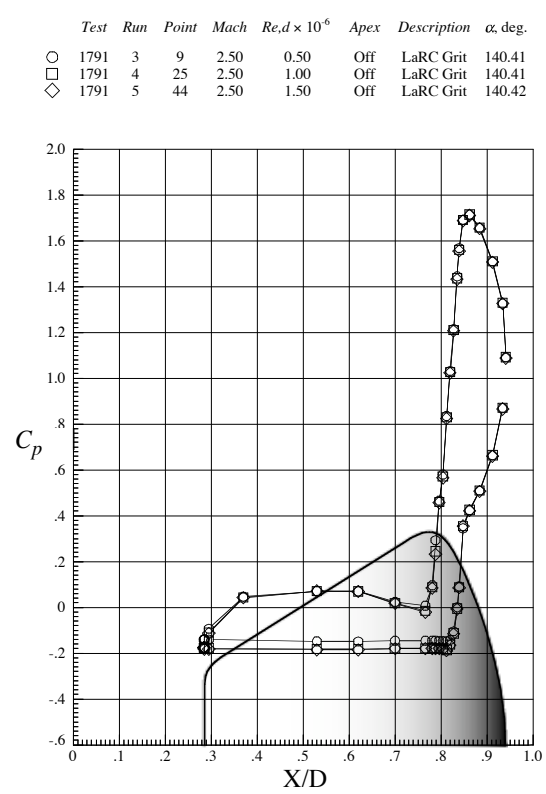

(a) $\square \approx 140^{\circ}$
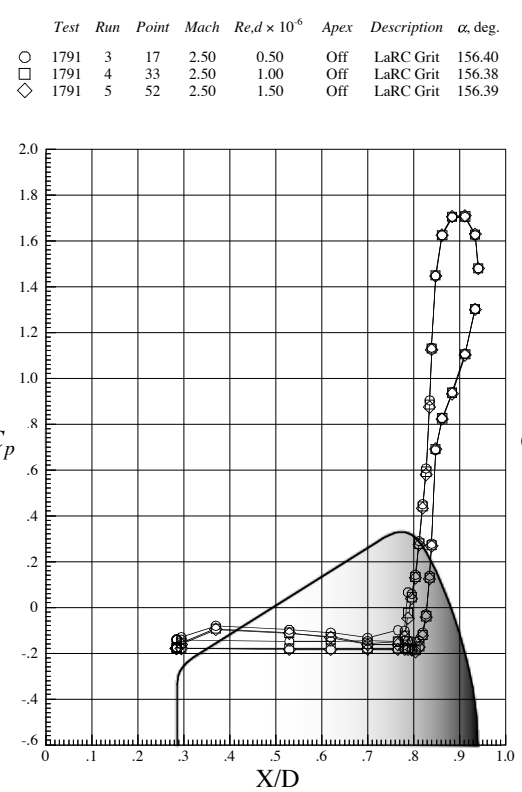

(b) $\square \approx 156^{\circ}$
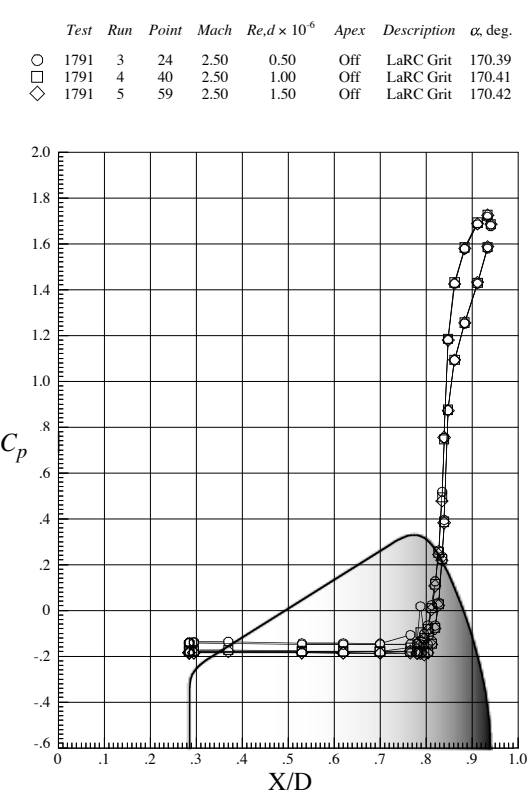

(c) $\square \approx 170^{\circ}$

Figure 28. Effect of Reynolds number on centerline surface static pressure data for CEV Model with LaRC Grit Pattern in the LaRC UPWT for $M=2.5$ at $\square \approx 140^{\circ}, \square \approx 156^{\circ}$, and $\square \approx 170^{\circ}$. 
Reproducibility: Figure 30 shows within-test reproducibility of centerline static surface pressure distributions at Mach 2.5 respectively. In order to generate uncertainty analyses as referred to in section 3.4, sets of repeat runs were done at the beginning and end of each test entry. These data sets were collected at a $\mathrm{Re}_{\mathrm{d}}=1.5 \times 10^{6}$ with LaRC grit applied to the model. In order to generate these repeat runs, transition grit was applied, removed, and then applied again. Therefore these runs show the within-test reproducibility relative to flow conditions, instrumentation, and model surface configuration. Although it cannot be observed from these plots due to the scale required to display the full range of data, reproducibility within the test was generally on the order of the ESP module rated accuracy, lending confidence to data trends and magnitudes. .

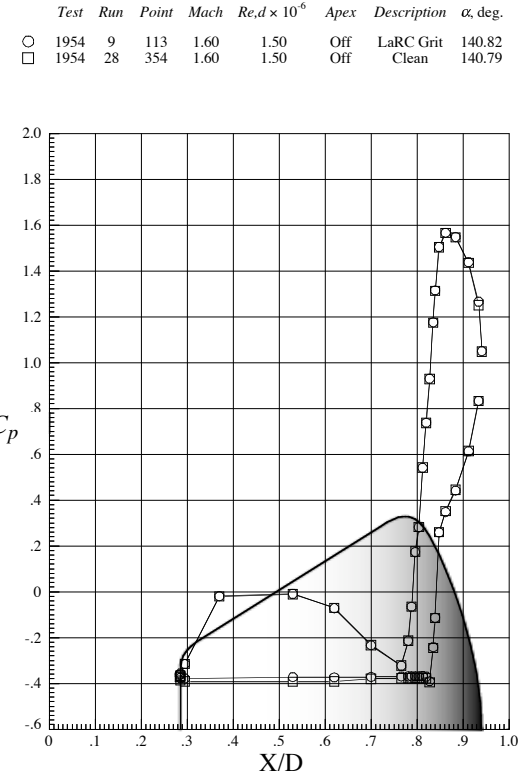

(a) $\square \approx 140^{\circ}$

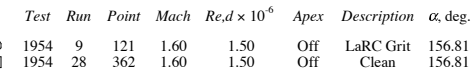

$\begin{array}{lllllllll}\circ & 1954 & 9 & 121 & 1.60 & 1.50 & \text { Off } & \text { LaRC Grit } & 156.81 \\ \square & 1954 & 28 & 362 & 1.60 & 1.50 & \text { Off } & \text { Clean } & 156.81\end{array}$

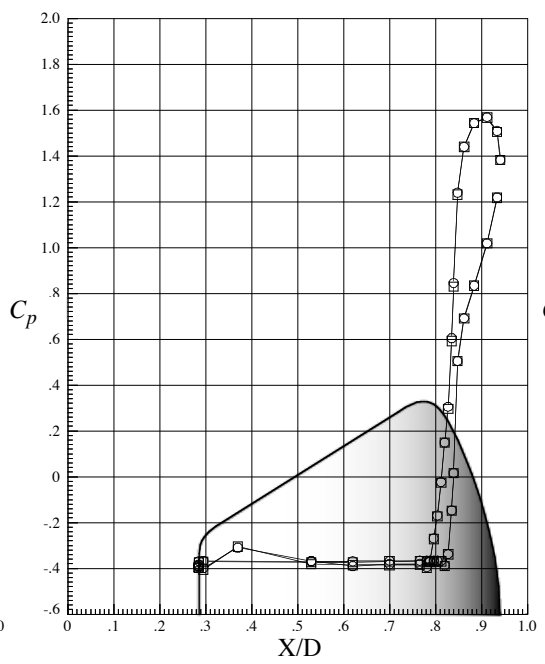

(b) $\square \approx 156^{\circ}$
Test Run Point Mach Re, $\square \square 10^{-6}$ Apex Description $\alpha$, deg.

$\begin{array}{lllllllll}\circ & 1954 & 9 & 128 & 1.60 & 1.50 & \text { Off } & \text { LaRC Grit } & 170.79 \\ \square & 1954 & 28 & 369 & 1.60 & 1.50 & \text { Off } & \text { Clean } & 170.82\end{array}$

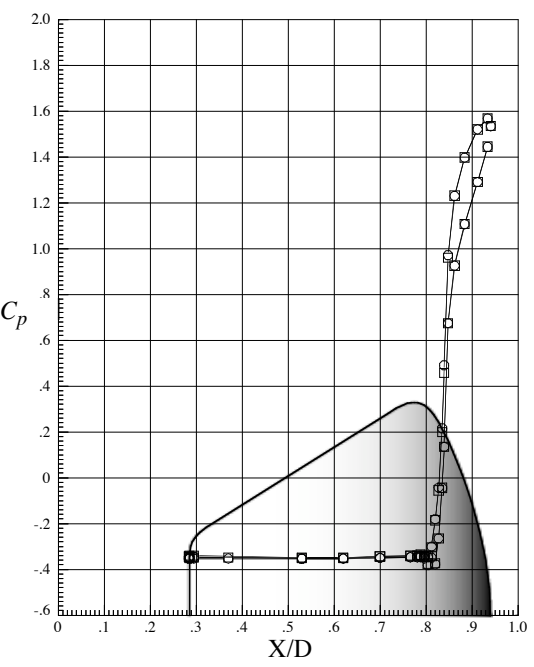

(c) $\square \approx 170^{\circ}$

Figure 29. Effect of grit on centerline surface static pressure data for CEV model in the LaRC UPWT for $M=1.6 . \operatorname{Re}_{d}=1.5 \times 10^{6}$. at $\Pi \approx 140^{\circ}$. $\Pi \approx 156^{\circ}$, and $\Pi \approx 170^{\circ}$.

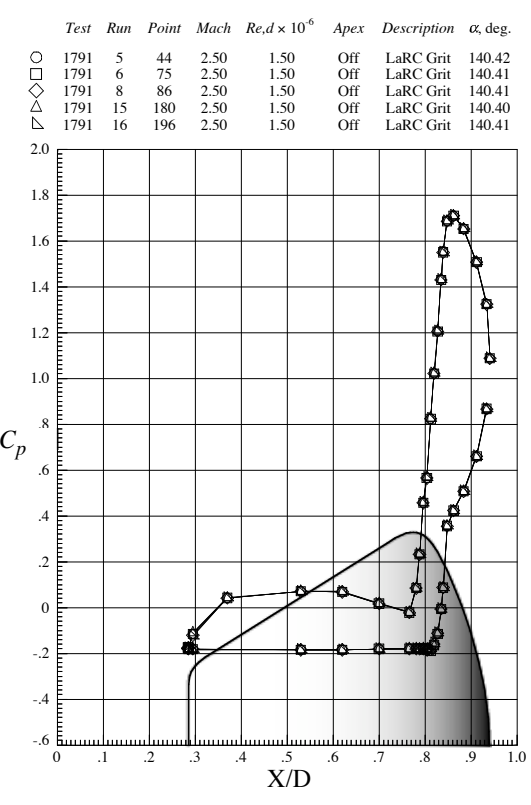

(a) $\square \approx 140^{\circ}$

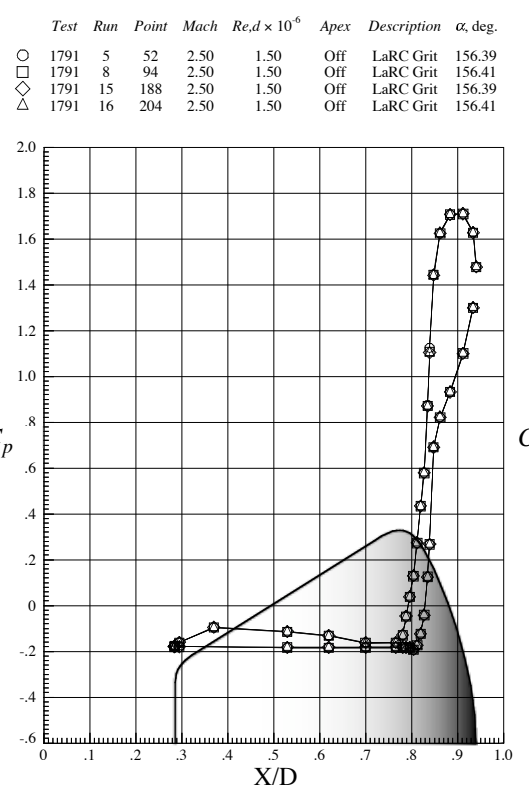

(b) $\square \approx 156^{\circ}$

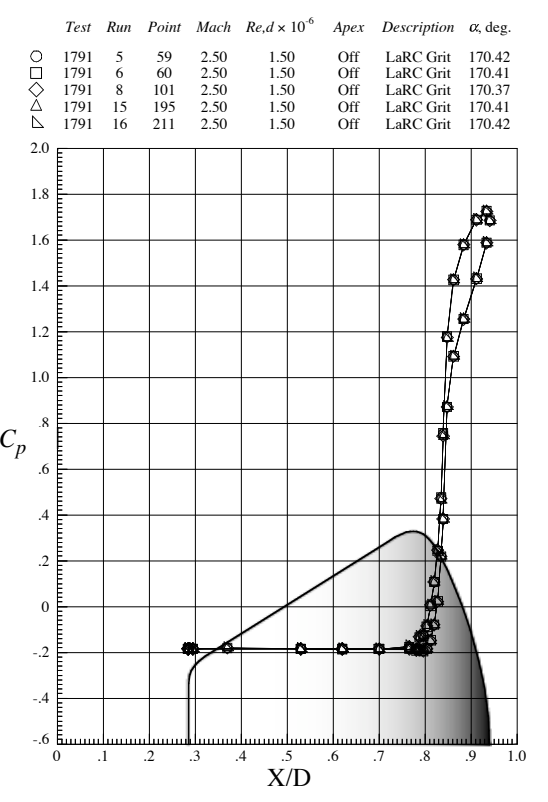

(c) $\square \approx 170^{\circ}$

Figure 30. Within-test reproducibility of centerline surface static pressure data for CEV model in the LaRC UPWT at $M=2.5, \operatorname{Re}_{\mathrm{d}}=1.5 \times 10^{6}$, at $\square \approx 140^{\circ}, \square \approx 156^{\circ}$, and $\square \approx 170^{\circ}$. 


\section{Summary and Conclusions}

A test program to provide aerodynamic information on the current Crew Exploration Vehicle configuration at supersonic test conditions was executed over a four-month period in NASA Langley's Unitary Plan Wind Tunnel. Virtual modeling tools allowed rapid use of infrared (IR) and temperature sensitive paint (TSP) thermography techniques to conduct transition studies. Aerodynamic and pressure testing of a 3.03\%-scale model of the current CEV configuration was completed in both test sections of the LaRC UPWT. Six-component force and moment data and static surface pressure data were obtained over an angle-of-attack range of $140^{\circ}$ to $170^{\circ}$ for Mach numbers $1.6,1.8,2.0,2.5,3.0$, and 4.5 , and Reynolds numbers $0.5 \square 10^{6}, 1.0 \square 10^{6}$, and $1.5 \square 10^{6}$ based on body diameter. The model was run with a clean surface, a distributed grit ring and centered on an average stagnation region, and full grit. The wind tunnel facility, hardware, and instrumentation performed as designed and the test matrices were executed as planned. For reentry orientations of 140 to 170 degrees (heat shield forward), windward surface flow was entirely laminar for freestream unit Reynolds numbers equal to or less than 3 million per foot. Optical techniques showed qualitative evidence of forced transition on the windward heat shield with application of distributed grit. Longitudinal static force and moment data showed the largest differences with Mach number and angle of attack variations. Data show the CEV configuration to be statically stable for the estimated center of gravity location, with stability increasing with increasing Mach number. The trim angle increases from approximately $144^{\circ}$ at the lowest Mach numbers $(\mathrm{M} \leq 2.0)$ to approximately $149^{\circ}$ at $\mathrm{M}=4.0$. For a given angle of attack, L/D values were constant with Mach number but vary from approximately 0.55 to 0.45 over the range of trim angles of attack observed for this Mach number range. Measurable aerodynamic effects of the apex cover are observed for pitching moment coefficient with decreasing angle of attack and Mach number. Aerodynamic data showed minimal sensitivity to Reynolds number or surface grit pattern for the configurations tested. Discrete static surface pressures on the vehicle forebody and aftbody supported the aforementioned trends with Mach number, Reynolds number, and angle of attack. Within-test and test-to-test reproducibility was generally on the order of the instrumentation accuracies, lending confidence to experimental methods and facility operations.

\section{Acknowledgments}

The authors wish to thank the numerous technicians and engineers at the Unitary Plan Wind Tunnel at the NASA Langley Research Center without whose dedication and innovation the experimental test program would not have been possible. Eric Walker is acknowledged and appreciated for his work generating aerodynamic uncertainty values. Grateful acknowledgement is also extended to James Bell, Jim Ross, Mike Hemsch, JoAnn Ingram, and Greg Brauckmann for their technical consultations.

\section{References}

\section{1. http://www.nasa.gov/missions/solarsystem/cev.html.}

2. Bell, J.S., Test 5-CA Final Report, CEV Program Document EG-CEV-06-19, March 2006.

3. Erickson, G.E., Overview of Selected Measurement Techniques for Aerodynamic Testing in the NASA Langley Unitary Plan Wind Tunnel, AIAA Paper 2000-2396, June 2000.

\section{Stivers, L.S., Effects of a Sting Support On the Supersonic Force and Moment Characteristics of an Apollo} Model at Angles From $-\mathbf{3 0}^{\circ}$ to $+\mathbf{1 8 5}^{\circ}$, NASA TM X-1081, December 1964.

5. Schwartz, R.J., Fleming, G.A., LiveView3D: Real Time Data Visualization for the Aerospace Testing Environment, AIAA-2006-1388, January 2006.

6. Liu, T., and Sullivan, J.P., Pressure and Temperature Sensitive Paints, Springer-Verlag, Berlin, 2005.

7. Daryabeigi, K., Borg, S., Wind Tunnel and Flight Flow Visualization Using Infrared Imaging, $37^{\text {th }}$ ISA International Instrumentation Symposium, San Diego, CA May 5-9. 1991. 
8. Braslow, Albert L, et. al., Use of Grit-Type Boundary-Layer-Transition Trips on Wind Tunnel Models, NASA TN-D-3579, September 1966.

9. Murphy, K.J., Test 1-CA Final Report, CEV Program Document EG-CEV-06-161, December 2005.

10. Murphy, K.J., Test 3-CA Final Report, CEV Program Document EG-CEV-06-137, February 2006.

11. Murphy, K.J., Test 7-CA Final Report, CEV Program Document EG-CEV-06-162, April 2006.

12. U.S. Guide to the Expression of Uncertainty in Measurement, ANSI/NCSL Z540-2-1997, October 1997.

13. Hemsch, M.J., et al., Measurement of Force Balance Repeatability and Reproducibility in the NTF, AIAA Paper 2004-771, January 2004. 